\title{
Evli Çiftlerde Bağlanma Boyutları ile Evlilik Doyumu Arasındaki İlişkide Evlilik Gücünün Aracı Rolü
}

\author{
Meryem Kaynak Malatyal1 ${ }^{1}$ \\ Ankara Üniversitesi
}

\author{
Ayda Büyükşahin Sunal² \\ Ankara Üniversitesi
}

\begin{abstract}
Özet
Bu çalışmanın temel amacı bağlanma boyutları (bağlanma kaygısı ve kaçınması) ile evlilik doyumu arasındaki ilişkide evlilik gücünün aracı rolünün araştıılmasıdır. Çalışmanın örneklemini 162 evli çift oluşturmuş̧ur. Veri toplama aracı olarak Yakın İlişkilerde Yaşantılar Envanteri-II, İlişki İstikrarı Ölçeği ve Çift Güç Ölçeği kullanılmıştır. Çalışma hipotezleri Aktör Partner Karşılıklı Bağımlılık Modeline (Kenny, Kashy ve Cook, 2006) aracı değişken çiftinin eklendiği, aracı değişkenli Aktör Partner Karşılıklı Bağımlılık Modeli (A-APKM, Ledermann, Macho ve Kenny, 2011) kullanılarak test edilmiştir. Sonuçta, hem erkeklerde hem de kadınlarda, bağlanma kaygısının bireyin kendi evlilik doyumunu, evlilik gücü aracıllı̆̆ ile yordadığı bulunmuştur. Diğer bir ifadeyle, hem kadınlarda hem de erkeklerde, bağlanma kaygısı arttıkça eşe yönelik algılanan güç azalmakta, eşe yönelik algılanan güç azaldıkça da evlilikten alınan doyum düşmektedir. Bağlanma kaçınmas1 ise kadınlarda doğrudan, erkeklerde ise hem doğrudan hem de evlilik gücü aracılığı ile bireyin kendi evlilik doyumunu olumsuz yönde yordamaktadır. Ayrıca, kadının bağlanma kaygısının eşin evlilik doyumunu olumsuz yönde yordadığı görülmüştür. Çalışmanın bulguları ve ileriki çalışmalar için öneriler tartışılmıştır.
\end{abstract}

Anahtar kelimeler: Bağlanma, bağlanma güvensizliği, evlilik gücü, evlilik doyumu, aktör partner karşılıklı bağımlılık modeli

\begin{abstract}
The main aim of this study was to investigate the mediating role of marital power on the relationship between attachment dimensions (attachment anxiety and avoidance) and marital satisfaction. Study sample consisted of 162 married couples. Instruments included Experiences in Close Relationships Inventory-Revised, Investment Model Scale and Couple Power Scale. Study hypotheses were tested by using Actor-Partner Interdependence Model with Mediation (APIMeM, Ledermann, Macho, \& Kenny, 2011) in which a pair of mediating variables were added to Actor-Partner Interdependence Model (APIM, Kenny, Kashy, \& Cook, 2006). Results showed that, for both husbands and wives, attachment anxiety predicted individuals' own marital satisfaction via their own marital power. In other words, for both husbands and wives, attachment anxiety decreased marital power, low marital power in turn decreased their marital satisfaction. Moreover, attachment avoidance negatively predicted individuals' own marital satisfaction directly for wives; directly and via marital power for husbands. Furthermore, women's attachment anxiety negatively predicted their partners' marital satisfaction. Findings of the study and suggestions for future research were discussed.
\end{abstract}

Keywords: Attachment, attachment insecurity, marital power, marital satisfaction, actor-partner interdependence model

Yazar notu: Bu çalışma, birinci yazarın Ankara Üniversitesi Sosyal Bilimler Enstitüsü Psikoloji (Sosyal) Anabilim Dalı’nda 2014 yılında tamamladığı yüksek lisans tez çalışmasından üretilmiştir.

Yazışma Adresi: ${ }^{1}$ Arş. Gör. Meryem Kaynak Malatyalı, Ankara Üniversitesi, Dil ve Tarih-Coğrafya Fakültesi, Psikoloji Bölümü, No: 45 Sihhiye / Ankara, mkaynak@ankara.edu.tr, ORC-ID: 0000-0003-2467-1207

${ }^{2}$ Doç. Dr., Ankara Üniversitesi, Dil ve Tarih-Coğrafya Fakültesi, Psikoloji Bölümü, bsahin@humanity.ankara.edu.tr, ORC-ID: 00000002-7535-1521

Gönderim Tarihi: 28.11 .2016

Kabul Tarihi: 19.12 .2018 
Güvensiz bağlanmanın ilişkilerde düşük doyumla ilişkili olduğu pek çok araştırmayla gösterilmiştir (örn., Butzer ve Campbell, 2008; Davila, Bradbury ve Fincham, 1998; Harma ve Sümer, 2016; Mikulincer ve Shaver, 2007). Özgül olarak, eşlerine yüksek düzeyde kaygılı ya da kaçınmacı olarak bağlanan bireylerin evliliklerinden daha düşük doyum aldığı pek çok çalışmayla ortaya koyulmuştur. Ayrıca, güvensiz bağlanan kişinin eşinin de evlilik doyumunun düşük olduğuna işaret eden bazı çalışmalar vardır (örn., Butzer ve Campbell, 2008; Harma ve Sümer, 2016). Güvensiz bağlanmanın kişinin hem kendisinin hem de eşinin evlilikten aldığ üzerindeki bu kritik etkisi göz önünde bulundurulduğunda, bu etkinin altında yatan mekanizmaların ortaya çıkarılması önem kazanmaktadır. Ek olarak, güvensiz bağlanma ile evlilik doyumu arasındaki ilişkide aracı mekanizmaların incelenmesinin, güvensiz bağlanma sorunu olan çiftlerle çalışan çift terapistlerine yol gösterici olacağ1 düşünülmektedir.

Alanyazında güvensiz bağlanma ile evlilik ve ilişki doyumu arasındaki ilişkide olumsuz duygulanım (Davila ve ark., 1998), çatışma algısı (Brassard, Lussier ve Shaver, 2009), düşük empati ve affetme (Chung, 2014) gibi süreçlerin aracılık ettiğini gösteren çalışmalar vardır. Ek olarak, bağlanma güvensizliğinin ilişkilerde algılanan düşük güçle (Lemay ve Dudley, 2009; Oka, Brown ve Miller, 2016) ve düşük gücün de ilişkiden alınan düşük doyumla (Brezsnyak ve Whisman , 2004; Kifer, Heller, Perunovic ve Galinsky, 2013; Zimbler, 2012) ilişkili olduğu bildirilmektedir. Buradan yola çıkarak, bağlanma kaygısı ve kaçınması ile düşük evlilik doyumu arasındaki ilişside evlilikte algılanan düşük gücün aracılık edebileceği öne sürülebilir. Bununla birlikte, evlilik ilişkileri için önemli bir faktör olan evlilik gücünün bu süreçteki etkisini inceleyen bir çalışmaya rastlanmamıştır. Bu doğrultuda, bu araştırmanın amacı bağlanma güvensizliğinin (yüksek bağlanma kaygısı ya da kaçınması) evlilik doyumu ile ilişkisini ve bu ilişkide evlilik gücünün aracı rolünü incelemektir. Bunun yanı sıra, daha önce de belirtildiği gibi, kişinin bağlanma güvensizliği eşinin evlilikten aldığ 1 doyumla da ilişsilidir (Butzer ve Campbell, 2008; Harma ve Sümer, 2016). Bu çalışmada bu durum da göz önünde bulundurulmuş ve bağlanma kaygısı ve kaçınmasının eşin evlilik doyumu ile ilişkisinin ve bu ilişkide evlilik gücünün aracı rolünün incelenmesi de çalışmanın bir diğer amacını oluşturmuştur.

\section{Bağlanma ve Evlilik Doyumu}

Aşk1 romantik partnere bağlanma olarak değerlendiren Hazan ve Shaver (1987), bağlanma kuramını geliştiren Bowlby'nin $(1969,1973)$ "içsel çalışan modeller" yaklaşımından yola çıkarak, erken dönem bağlanma biçimlerinin (Ainsworth, Bleher, Waters ve Wall, 1978) bi- reylerin yetişkinlikte kurdukları romantik ilişkilerde de devam ettiğini öne sürmüşlerdir. Buna göre, yetişkinler romantik partnerlerine üç biçimde bağlanabilirler: güvenli, kaçınmacı ve kaygılı/kararsız. Daha sonraki çalışmalarda ise yetişkinlikte bağlanmaya boyutsal bir yaklaşım getirilerek bireylerin kendileri ile ilgili algıları ya da bağımlılık boyutu "kaygl", diğerleri ile ilgili algıları boyutu ise "kaçınma" olarak değerlendirilmiştir (Brennan, Clark ve Shaver; 1998; Fraley ve Waller, 1998). Buna göre, kaygı boyutu bireylerin yakın ilişkilerde terk edilme ya da reddedilmeye yönelik duyarlılığını ve bağlanma kaygısını; kaçınma boyutu ise bireylerin diğerlerine bağımlı ve yakın olmaktan duydukları rahatsızlığı ifade etmektedir.

Bağlanma kaygısı bireyin kendi benliğine ilişkin "yetersiz", "değersiz" ve "sevilmeye layı olmayan" gibi zihinsel temsillerle ilişkiliyken, diğerlerine yönelik birbiriyle çelişen inançlarla ilişkilidir (Mikulincer ve Shaver, 2007). Bağlanma kaygısı yüksek olanlar bir yandan diğerlerinin iyi olduğuna dair umutlu olmalarına rağmen diğer yandan diğerlerinin güvenilmez, erișilmez ve sadakatsiz olduğunu da düşünme eğilimindedirler. Bağlanma kaçınması ise diğerleri hakkında değişmez bir şekilde olumsuz temsillerle ilişkilidir (Mikulincer ve Shaver, 2007). Diğer bir ifadeyle, bağlanma kaçınması yüksek olan bireyler değişmez bir şekilde diğerlerinin kötü ve güvenilmez olduğuna inanırlar. Bağlanma kaçınması yüksek olanların kendi benliklerine ilişkin temsilleri ise olumludur, ancak Mikulincer ve Shaver'a (2007) göre, bu olumlu algı çoğunlukla aşırı abartılmıştır, gerçekçi değildir ve benliği tehditlere karşı korumaya yöneliktir.

Kişinin hem kendi benliği hem de diğerlerine bakış açısıyla ilişkili olan bağlanma boyutlarının ilişkilerden alınan doyum üzerinde de etkili olduğu bildirilmektedir (Mikulincer ve Shaver, 2007). Uzun süreli ilişkiler bağlamında doyum 'sevilme, yakınlık, ilgi görme, kabul edilme, anlaşılma, desteklenme ve güvenlik gibi isteklerle ilgili ihtiyaçların yanı sıra; özerklik, gelişim ve yeterlilik gibi bireysel isteklerle ilgili ihtiyaçların karşılanması' olarak tanımlanmakta ve 'bağlanma kuramına göre ilişki doyumunun eşlerin yakınlık, güvenli liman ve güvenli dayanak ihtiyaçlarını etkili bir şekilde karşılama düzeyine bă̆ll olduğu' bildirilmektedir (Mikulincer ve Shaver, 2007, s. 308). Bağlanma kaygısı ve bağlanma kaçınmasının ise evlilikte kötü işleyiş ve düşük doyumla ilişkili olduğu belirtilmektedir (Mikulincer ve Shaver, 2007). Buna göre, bağlanma kaygısı ve bağlanma kaçınması her evlilikte ortaya çıkabilecek ilişkisel problemlere işlevsiz tepkiler verilmesi ile (yapışkan bir şekilde eşin ilgisini çekmeye çalışma ya da eşten tamamen uzaklaşma gibi) ve bunun sonucunda da eşlerin doyumsuzluk yașamasıyla ilișkilidir.

Özgül olarak, bağlanma kaygısı yükseldikçe birey- 
lerin eşlerine yönelik kıskançlıkları (Hazan ve Shaver, 1987; Knobloch, Solomon ve Cruz, 2001), ilişkilerinde çatı̧̧ma algılama ihtimalleri (Campbell, Simpson, Boldry ve Kashy, 2005; Harma ve Sümer, 2016), eşleri ile etkileşimlerine yönelik olumsuz beklentileri (Baldwin, Fehr, Keedian, Seidel ve Thomson, 1993) ve çatışmalarda olumsuz duyguları deneyimleme ve bunları yıkıcı bir şekilde ifade etme ihtimalleri (Özen, 2012) gibi işlevsiz tepkilerinin arttığı görülmektedir. Ayrıca, bağlanma kaygısı yüksek olan bireylerin ilişkilerinde yüksek düzeyde bedel rapor ettikleri (Pistole, Clark ve Tubbs, 1995) ve romantik ilişkilerini düşünürken ilişkiye dair kayıpları daha fazla vurguladıkları (Boon ve Griffin, 1996) bildirilmiş̧tir.

Alanyazında, yüksek düzeyde bağlanma kaçınmasının eșe yönelik değișmez bir olumsuz bakıș açısı ve eșe daha az yakınlaşma ile ilişsili olduğu rapor edilmektedir (Mikulincer ve Shaver, 2007). Partnerle ilişkilerde araya mesafe koymak ise ülkemiz gibi karşılıklı bağımlılık ve uyum gibi değerlerin önemli olduğu toplumlarda ilişkiler için yıkıcı olabilmektedir (Harma ve Sümer, 2016). Ayrıca bağlanma kaçınması yüksek bireylerin ilişsisel ödüllere duyarlılıkları da daha düşüktür (Laurenceau, Kleinman, Kaczynski ve Carver, 2010). Diğer bir ifadeyle, bu bireyler ilişkilerinde ödüllendirilseler bile bunu fark etme ihtimalleri düşüktür ve bu da onların evliliklerine ilişkin algılarını etkileyebilmektedir.

Sonuç olarak, farklı şekillerde de olsa, bağlanma kaygısı ve kaçınmasının her iki çiftin de evlilikten aldığı doyumu düşürdüğü bildirilmektedir (Butzer ve Campbell, 2008; Davila ve ark., 1998; Harma ve Sümer, 2016; Mikulincer ve Shaver, 2007). Mevcut çalışmada da, önceki çalışmaların bulguları ile tutarlı olarak, hem bağlanma kaygısının hem de bağlanma kaçınmasının, kişinin hem kendisinin hem de eşinin evlilikten aldığı doyumu düşürmesi beklenmektedir. Diğer bir ifadeyle, bağlanma kaygısı ve bağlanma kaçınmasının bireyin kendisinin (Hipotez 1) ve eşinin (Hipotez 2) evlilik doyumunu olumsuz yönde yordaması beklenmektedir.

\section{Bağlanma Boyutları ile Evlilik Doyumu Arasındaki İlişkide Evlilik Gücünün Aracı Rolü}

Alanyazında pek çok farklı şekilde tanımlanan güç, özetle, bireyin kendi amaçlarına ulaşabilmek için sosyal çevresindeki diğerlerinin davranış, kazanç ya da kaynaklarını etkileyebilme ve onları değiştirebilme yeteneği ya da potansiyeli olarak tanımlanabilir (bkz. Simpson, Farrell, Orina ve Rothman, 2015). Cromwell ve Olsen ise (1975), gücün üç bileşenli bir yapı olduğunu öne sürmüştür: gü̧c temelleri, güç süreçleri ve güç sonuçlarl. Güç temelleri, bireylerin evliliklerinde eşlerini kontrol etmek için kullanabilecekleri kaynaklardır (örn., ekonomik güç ve çekicilik gibi). Güç süreçleri, bireylerin eşle- ri ile etkileşimleri esnasında kararlılık, çaba ve ikna gibi iletişim tekniklerini kullanarak ilişkide kontrolü sağlama girişimleridir. Güç sonuçları ise, evlilikte alınan kararlar üzerinde bireylerin ne kadar etkin olduğudur. Mevcut çalışmada da, Cromwell ve Olsen'ın (1975) yaklaşımından yola çıkılarak, güç süreçleri ve alınan kararlardaki etkinlik açısından eşleri üzerinde kendisini daha etkili algılayan bireyler daha güçlü kabul edilmektedir.

Bireylerin evliliklerinde algıladıkları güç, bağlanma örüntülerinden bağımsız değildir (Simpson ve ark., 2015). Pek çok araştırma da bağlanma güvensizliğinin ilişkilerde algılanan düşük güçle ilişkili olduğunu göstermektedir (Lemay ve Dudley, 2009; Oka ve ark., 2016). Lemay ve Dudley (2009, Çalışma 2 ve Çalışma 3) kronik güvensiz bağlanmanın bir göstergesi olarak bağlanma kaygısını ele almıș ve bağlanma kaygısı yüksek bireylerin ilişkilerinde kendilerini daha güçsüz algıladıklarını ortaya koymuştur. Oka ve arkadaşları (2016) ise çiftlerle yürüttükleri çalışmalarında bağlanma kaygısı ve kaçınması puanlarını birleştirerek bağlanma güvensizliği puanı olușturmuş ve sonuçta bağlanma güvensizliğinin her iki çiftte de evlilikte düşük güçle ilişkili olduğunu bulmuştur. Bilgimiz dâhilinde, alanyazında bağlanma kaçınması ile evlilik gücü arasındaki ilişkiyi doğrudan ölçen bir çalışma bulunmamakla birlikte, Rogers, Bidwell ve Wilson (2005), hem bağlanma kaçınması hem de bağlanma kaygısı arttıkça eşe yönelik algılanan güçten memnun olma düzeyinin düştüğünü göstermiştir.

Bu çalışmada da, önceki çalışmaların bulguları ile tutarlı olarak, hem bağlanma kaygısının hem de bağlanma kaçınmasının evlilikte eşe yönelik algılanan düşük güçle ilişkili olması beklenmektedir. Şöyle ki, ihtiyaçlarının karşılanacağından emin olmayan ve bunun için sürekli alarm halinde olan bağlanma kaygısı yüksek bireylerin ve ihtiyaçlarının karşılanmayacağından emin olan bu nedenle kendini tamamen geri çeken bağlanma kaçınması yüksek bireylerin (Mikulincer ve Shaver, 2007) evlilikte eşlerini etkileme yeteneklerini düşük algılaması beklenmektedir. Diğer bir ifadeyle, bağlanma kaygısı yüksek bireylerin ilişkilerinde eşlerine ihtiyaçlarının karşılanacağı konusunda güvenmemeleri ve bunu sağlamak için sürekli bir uğraş içinde olmaları ya da ilişkilerine aşırı odaklanmaları dolayısıyla eşlerine yönelik kendilerini daha güçsüz algılamaları beklenmektedir. Bağlanma kaçınması yüksek olan bireyler ise, ihtiyaçlarının karşılanmayacağı konusunda eşlerine kesin olarak güvenmemekte ve bu konuda bir çaba da sarf etmemektedirler. Buradan yola çıkarak, bağlanma kaçınmasının da bireyin eşine karşı algıladığı gücü düşürmesi beklenmektedir.

Güvensiz bağlanma ile ilişkili olduğu belirtilen düşük güç algısı ise evlilikte çeşitli problemlerle (örn., Babcock, Waltz, Jacobson ve Gottman, 1993; Sagresta- 
no, Heavey ve Christensen, 1999) ve düşük evlilik ve ilişki doyumuyla ilişkilidir (Brezsnyak ve Whisman, 2004; Kifer ve ark., 2013; Zimbler, 2012). İlk olarak, düşük gücün kişilerin kalp sağlığı açısından olumsuz etkilerinin olduğu bulunmuştur (Scheepers, Wit, Ellemers ve Sassenberg, 2012). Buna göre, yüksek güce sahip olmak kişilerde sağlık için elverişli olan bir kardiyovasküler örüntüye neden olurken, düşük güce sahip olmak sağlık için elverişsiz olan bir kardiyovasküler örüntüye neden olmaktadır. Anderson ve Berdahl (2002) ise kişilik olarak baskın olmayan ve güçsüz bireylerin olumsuz duyguları olumlu duygulardan daha fazla deneyimlediklerini ve çevresel tehditlere daha fazla odaklandıklarını bulmuşlardır. Ek olarak, yüksek gücün bireylerin öznel iyilik halini olumlu yönde yordadığı (Kifer ve ark., 2013) ve güçlü bireylerin diğerlerinin duygu ve düşüncelerini daha iyi anladığı bildirilmektedir (Schmid-Mast, Jonas ve Hall, 2009).

Evli erkeklerde düşük gücün saldırganlık düzeyini artırdığı (Sagrestano ve ark., 1999) ve eşlerine göre daha az güce sahip olan erkeklerin eşlerine daha fazla fiziksel istismar uyguladıkları bildirilmektedir (Babcock ve ark., 1993). Kadınlarda ise düşük gücün depresyonla ilişkili olduğu bildirilmektedir (Byrne ve Carr, 2000). Ayrıca, ilişkilerinde alınan kararlarda yüksek güce sahip olduğunu rapor eden kadınların düşük güce sahip olduğunu rapor edenlere kıyasla benlik saygılarının daha yüksek olduğu bildirilmektedir (Galliher, Rostosky, Welsh ve Kawaguchi, 1999). Sonuç olarak, yüksek güç algısının pek çok olumlu çıktıyla, güçsüzlük algısının ise pek çok olumsuz çıktıyla ilişkili olduğu anlaşılmaktadır. Ayrıca, gücün evlilik ve ilişki doyumu ile olumlu yönde ilişkili olduğunu gösteren pek çok çalışma vardır (Brezsnyak ve Whisman, 2004; Kifer ve ark., 2013; Zimbler, 2012). Buna göre, evlilik gücü arttıç̧a bireylerin evlilikten aldıkları doyum da yükselmektedir.

$\mathrm{Bu}$ çalışmada da bağlanma kaygısı ve bağlanma kaçınması sonucunda algılanan düşük evlilik gücünün evlilikten alınan düşük doyumla sonuçlanması beklenmektedir. Diğer bir ifadeyle, hem bağlanma kaygısının hem de bağlanma kaçınmasının bireyin ve/veya eşinin evlilik gücünü düşürmesi; bireyin ve/veya eşinin düşük evlilik gücünün ise bireyin evlilik doyumunu düşürmesi beklenmektedir (Hipotez 3). Ayrıca, daha öncede belirtildiği gibi, düşük güç yalnızca bireyi değil, evliliği ve dolayısıyla eşi de olumsuz etkilemektedir (örn., Babcock ve ark., 1993; Oka ve ark., 2016; Sagrestano ve ark., 1999). Bu nedenle, bağlanma kaygısı ve kaçınması sonucunda algılanan düşük gücün eşin evlilikten aldığı doyumu da düşürmesi beklenmektedir. Diğer bir ifadeyle, bağlanma kaygısı ve kaçınmasının bireyin ve/veya eşinin düşük evlilik gücü aracılığıyla eşin evlilik doyumunu olumsuz yönde yordaması beklenmektedir (Hipotez 4).

\section{Yöntem}

\section{Katılımcılar}

Çalışmaya kartopu örneklemesi yöntemiyle ulaş1lan 164 evli çift katılmıştır. iki çift, eşlerden en az biri uç veri içerdiği için çalışmadan çıkartılmıştır. Analizler geriye kalan 162 çiftle yürütülmüştür. Katılımcıların yaşları 21 ile 54 arasında değişmektedir ve yaş ortalamaları 31.44 'tür $\left(S=4.74\right.$; Ort $_{\text {kadin }}=30.20, S=4.25$; Ort. $_{\text {erkek }}=$ $32.67, S=4.88$ ). Çalışma durumu açısından değerlendirildiğinde, 129 kadının ve 157 erkeğin bir işte çalıştı̆̆ 28 kadın ve iki erkeğin herhangi bir işte çalışmadığı bildirilmiştir. Katılımcıların eve giren aylık geliri 800 TL ile $15000 \mathrm{TL}$ arasında değişmektedir ve eve giren aylık geliri ortalama 4429.30 TL'dir $(S=1891.79$ TL). Kat1lımcıların evlilik süresi üç ay ile 22.50 yıl arasında değişmektedir (Ort evlilik süresi $=5.47 \mathrm{y} 11, S=4.03$ ). Katılımcılara sahip oldukları çocuk sayısı sorulmuş ve 63 (\%38.9) çift çocuk sahibi olmadığını; 57 (\%35.2) çift bir çocuk sahibi olduğunu; 35 (\%21.6) çift iki çocuk sahibi olduğunu ve $4(\% 2.5)$ çift üç çocuk sahibi olduğunu rapor etmiştir.

\section{Veri Toplama Araçları}

Kişisel bilgi formu. $\mathrm{Bu}$ formda katılımcılardan cinsiyet, yaş, eğitim düzeyi, çalışma durumu gibi kişisel bilgileri yanıtlamaları istenmiştir. Ayrıca katılımcılara evlilik süresi ve varsa çocuk sayısı sorulmuştur. Son olarak, katılımcıların ekonomik durumlarına ilişkin sorular bu formda yer almıştır.

Çift Güç Ölçeği. Katılımcıların evlilik gücünü ölçmek amaciyla Brigham Young Üniversitesi'nde yürütülen Olgunlaşan Aileler Projesi (The Flourishing Families Project, Day ve ark., 2016) kapsamında oluşturulan Çift Güç Ölçeği kullanılmıştır. Projede yer alan araştırmacılar evlilerde gücü araştıran önceki çalışmalarda (Ball, Cowan ve Cowan, 1995; Crosbie-Burnett ve Giles-Sims, 1991; Lindahl, Malik, Kaczynski ve Simons, 2004; Sagrestano ve ark., 1999) kullanılan ölçeklerden maddeler alarak evlilik gücü indeksini (marital power index, Bogue, Miller ve Day, 2008'den akt., Oka ve ark., 2016) oluşturmuşlardır. Ölçek "Eşim beni dinlemez.", "Evlilik sorunlarımızla ilgili görüşlerimi eşime rahatça anlatabilirim.” (ters kodlu) ve "Parasal konularda son sözü söyleyen genellikle eşim olur." gibi 15 maddeden oluşmaktadır. Katılımcılar ölçek maddelerine ne düzeyde katıldıklarını beş dereceli ( 1 = Kesinlikle katıliyorum, 5 = Kesinlikle katılmıyorum $)$ bir ölçek üzerinden cevaplamışlardır. Önceki çalışmalarda (örn., Oka ve ark., 2016) tek faktörlü olarak kullanılan ölçek, Cromwell ve Olsen'ın (1975) önerdiği kuramsal çerçeve doğrultusunda "güç süreçleri” ve "güç sonuçla$r l$ " olarak adlandırılan iki alt faktör şeklinde de kullanılabilmektedir. Mevcut çalışmada da ölçek, önceki çalışmalardaki (örn., Oka ve ark., 2016) gibi tek faktörlü ola- 
rak değerlendirilmiştir. Ölçek, Kaynak-Malatyalı (2014) tarafından Türkçeye uyarlanmıştır ve Türkçe formunun geçerli ve güvenilir bir ölçme aracı olduğu bulunmuştur. Ölçeğin Türkçe formuna ait iç tutarlılık katsayısı Kaynak-Malatyalı (2014) tarafindan 87 olarak hesaplanmıştır. Mevcut çalışmada iç tutarlık katsayısı erkekler için .85 ve kadınlar için .87 olarak hesaplanmıştır. Ters kodlu maddeler (6. ve 8. maddeler) yeniden kodlandiktan sonra tüm maddelerin ortalaması alınarak evlilik gücü puanı oluşturulmuştur. Katılımcıların evlilik gücü puanlarının azalması onların evliliklerinde eşlerini kendilerinden daha etkili algıladıklarını göstermektedir. Diğer bir ifadeyle, evlilik gücü puanlarının düşmesi katılımcıların evliliklerinde kendilerini eşlerinden daha etkisiz algıladıklarına işaret etmektedir.

İlișki İstikrarı Ölçeği. Rusbult, Martz ve Agnew (1998) tarafından geliştirilmiştir. Ölçeğin ilişki doyumu (örn., "İlişkimiz benim için doyum verici."), ilişki yatırımı (örn., "İlişkimize çok fazla bağlandığımı ve bu ilişkiye çok şey verdiğimi düşünüyorum.”), seçeneklerin niteliğini değerlendirme (örn., "Birlikte olduğum kișiyle çıkmıyor olsaydım, bir şey değişmezdi, çekici bir başka kişi bulabilirdim.") ve bağlanım (örn., "Birlikte olduğum kişiye ve ilişkimize çok bağlanmış hissediyorum.”) olmak üzere dört alt boyutu vardır. Bağlanım alt boyutu yedi maddeden diğer alt boyutlar 10 maddeden oluşmaktadır. Bağlanım boyutunda yer alan maddeler dokuz dereceli Likert tipiyken $(1=$ Tamamen yanlış, $9=$ Tamamen doğru $)$, diğer alt boyutların ilk beş maddesi dört dereceli Likert tipi ( $1=$ Tamamen yanlış, 4 = Tamamen doğru); son beş maddesi dokuz dereceli Likert tipidir ( 1 = Tamamen yanlış, $9=$ Tamamen doğru). Bu alt boyutlarda, ilk beş madde son beş maddenin ölçme kalitesini artırmak amacıyla uygulanmaktadır. Rusbult ve arkadaşları (1998) tüm maddelerin uygulanmasını fakat analizlerin, her boyut için, son beş madde ile yürütülmesini önermektedir. Ölçek, Büyükşahin, Hasta ve Hovardaoğlu (2005) tarafindan Türkçeye uyarlanmıştır. Bu çalışmada katılımcılara tüm ölçek uygulanmış ancak ölçeğin yalnızca ilişki doyumu alt boyutu kullanılmıştır ve bu alt ölçekte yer alan son beş maddenin ortalaması alınarak katılımcıların evlilik doyumu puanı oluşturulmuştur. Bu puanların artması evlilik doyumunun arttığına işaret etmektedir. İlişki doyumu alt boyutunun iç tutarlık katsayısı Büyükşahin ve ark. (2005) tarafindan .90 olarak hesaplanmıştır. Mevcut çalışmada ise ilişki doyumu alt boyutunun iç tutarlık katsayısı kadınlar için .97 erkekler için .96 olarak hesaplanmıştır.

Yakın İlişkilerde Yaşantılar Envanteri-II (YİYE-II). Bu çalışmada yetişkinlerde bağlanmayı ölçmek amacıyla Fraley, Waller ve Brennan'ın (2000) geliştirdiği Yakın İlișkilerde Yaşantılar Envanteri-II kullanılmıştır. Ölçek 7'li Likert tipi ( 1 = Hiç katılmıyorum, 7
= Tamamen katıllyorum) 36 maddeden oluşmaktadır. Ölçeğin kaçınma (örn., "Romantik ilişkide olduğum kişilere fazla yakın olmamayı tercih ederim.”) ve kayg1 (örn., "Birlikte olduğum kişinin sevgisini kaybetmekten korkarım.”) olarak adlandırılan ve 18'er maddeden oluşan iki alt boyutu vardır. Ölçeğin Türkçeye uyarlaması Selçuk, Günaydın, Sümer ve Uysal (2005) tarafından yapılmıştır ve bu çalışmada ölçeğin özgün halindeki gibi iki faktörlü yapıya sahip olduğu bulunmuştur. Türkçe ölçeğin iç tutarlık katsayıları Selçuk ve arkadaşları (2005) tarafindan kaygı alt boyutu için .86, kaçınma alt boyutu içinse 90 olarak hesaplanmıştır. Mevcut çalışmada kayg1 alt boyutuna ait iç tutarlık katsayıları kadınlar için .86 ve erkekler için .83 olarak; kaçınma alt boyutuna ait iç tutarlık katsayıları kadınlar için .89 ve erkekler için .87 olarak hesaplanmıştır. Katılımcıların bağlanma kaygısı ve bağlanma kaçınması puanları bu boyutlara karşılık gelen maddelerin ortalaması alınarak hesaplanmıştır. Bireylerin bağlanma kaygısı ve bağlanma kaçınması puanlarının artması sırasıyla bağlanma kaygıları ve bağlanma kaçınmalarının arttığına işaret etmektedir.

İşlem

Katılımcılara kartopu örneklemesi yöntemiyle ulaşılmıştır. Ölçekler katılımcılara zarf içerisinde verilmiş ve sonrasında onlardan kapalı zarf içerisinde geri alınmıştır. Katılımcılar ölçek formunun ilk sayfasında çalışmanın konusu hakkında bilgilendirilmiş ve katılımcıların gönüllü katılımına ilişkin onayı alınmıştır. Ölçek formunda sırasıyla kişisel bilgi formu, Yakın İlişkilerde Yaşantılar Envanteri-II, Çift Güç Ölçeği ve İlişki İstikrar1 Ölçeği bulunmaktadır. Tüm katılımcılar ölçekleri aynı sırada yanıtlamışlardır.

\section{Bulgular}

İlk olarak, evlilik doyumu ve evlilik gücü ile aylık gelir, çocuk sayısı ve evlilik süresi arasındaki ilişkiler incelenmiş ve evlilik doyumunun hem kadınlarda $(r=-.20$, $p=.013)$ hem erkeklerde $(r=-.26, p=.001)$ çocuk sayıs1 ile olumsuz yönde ve anlamlı olarak ilişkili olduğu; aylık gelir (kadınlar için $r=.02, p=.76$; erkekler için $r=.08$, $p=.29$ ) ve evlilik süresi (kadınlar için $r=-.06, p=.47$; erkekler için $r=-.12, p=.13$ ) ile ise anlamlı bir ilişki göstermediği görülmüştür. Bu nedenle sonraki analizlerde çocuk sayısı değişkeni kontrol edilmiştir. Evlilik gücünün ise, ne kadınlarda ne de erkeklerde, çocuk sayısı (kadınlar için $r=-.14, p=.08$; erkekler için $r=-.08, p$ $=.29$ ), evlilik süresi (kadınlar için $r=-.01, p=.89$; erkekler için $r=-.14, p=.08$ ) ve aylık gelir (kadınlar için $r=.12, p=.13$; erkekler için $r=.04, p=.62$ ) ile anlaml 1 düzeyde ilişkili olduğu bulunmuştur. Sonrasında çalışmanın ana değişkenleri (bağlanma kaygısı, bağlanma ka- 
Tablo 1. Çalışma Değişkenlerine ait Betimleyici İstatistikler ve Çalışma Değişkenleri Arasında Çocuk Sayısı Kontrol Edilerek Hesaplanan Kısmi İlişkiler

\begin{tabular}{|c|c|c|c|c|c|c|c|c|}
\hline & 1 & 2 & 3 & 4 & 5 & 6 & 7 & 8 \\
\hline 1. K (Kadın) Bağlanma Kaygısı & - & & & & & & & \\
\hline 2. E (Erkek) Bağlanma Kaygısı & $.45^{* *}$ & - & & & & & & \\
\hline 3. K Bağlanma Kaçınması & $.54 * *$ & $.39 * *$ & - & & & & & \\
\hline 4. E Bağlanma Kaçınması & $.34 * *$ & $.51 * *$ & $.47 * *$ & - & & & & \\
\hline 5. K Evlilik Gücü & $-.51 * *$ & $-.26 * *$ & $-.35 * *$ & $-.22 * *$ & - & & & \\
\hline 6. E Evlilik Gücü & $-.33 * *$ & $-.46 * *$ & $-.23 * *$ & $-.40 * *$ & $.38 * *$ & - & & \\
\hline 7. K Evlilik Doyumu & $-.43 * *$ & $-.23 * *$ & $-.46 * *$ & $-.24 * *$ & $.49 * *$ & $.32 * *$ & - & \\
\hline 8. E Evlilik Doyumu & $-.38 * *$ & $-.35 * *$ & $-.31 * *$ & $-.54 * *$ & $.30 * *$ & $.43 * *$ & $.42 * *$ & - \\
\hline Ortalama & 3.31 & 3.11 & 2.29 & 2.37 & 3.78 & 3.78 & 7.80 & 7.97 \\
\hline Standart Sapma & 1.01 & .90 & .98 & .92 & .74 & .71 & 1.47 & 1.32 \\
\hline
\end{tabular}

Not. ${ }^{*} p<.05 ; * * p<.01$.

çınması, evlilik gücü ve evlilik doyumu) arasında çocuk sayısının kontrol edildiği kısmi ilişkiler hesaplanmıştır. Tablo 1'de görülebileceği gibi değişkenler arasındaki tüm ilişkiler beklenen yönde ve anlamlıdır. Sonuçlar, evlilik doyumunun evlilik gücüyle olumlu yönde, bağlanma kaygısı ve bağlanma kaçınmasıyla olumsuz yönde ve anlamlı ilişkilerinin olduğunu göstermiştir. Evlilik gücü ise bağlanma kaygısı ve bağlanma kaçınması ile olumsuz yönde ve anlamlı olarak ilişkilidir.

Çalışma değişkenleri (bağlanma kaygısı, bağlanma kaçınması, evlilik gücü ve evlilik doyumu) üzerindeki cinsiyet farklılıklarının incelenmesi amacıyla çocuk sayısı değişkeni kontrol edilerek tekrarlı ölçümler için varyans analizi uygulanmıştır. Analiz sonuçları, çocuk sayısının etkisi kontrol edildikten sonra, bağlanma kaçınması, $F(1,160)=.35, p=.56$, bağlanma kaygısı, $F(1$, $160)=.92, p=.34$, evlilik gücü, $F(1,160)=.23, p=.63$ ve evlilik doyumu, $F(1,160)=1.91, p=.17$, üzerinde anlamlı bir cinsiyet farkının olmadığına işaret etmiştir.

Çalışmanın hipotezleri, ayırt edilebilir çiftler (örn., karı-koca) için Aktör Partner Karşılıklı Bağımlılık Modeline (APKM, Kenny, Kashy ve Cook, 2006) aracı değişkenin eklendiği aracı değişkenli Aktör Partner Karş1lıklı Bağımlılık Modeli (A-APKM, Ledermann, Macho ve Kenny, 2011) kullanılarak AMOS programı üzerinden test edilmiştir. Bu modelde, aktör etkisi bireyin bağımsız değişkeninin kendi bağımlı değişkeni üzerindeki etkisini ifade ederken; partner etkisi aynı bağımsız değişkenin eşin bağımlı değişkeni üzerindeki etkisini ifade etmektedir (Kenny ve ark., 2006). Mevcut çalışmada öne sürülen model Şekil 1'de sunulmuştur. Modelde bağımsız değişkenler kadın ve erkek eşin bağlanma kaygısı $\left(X_{1}\right)$ ve bağlanma kaçınması $\left(\mathrm{X}_{2}\right)$, aracı değişkenler kadın ve erkek eşin evlilik gücü $(\mathrm{M})$ ve bağımlı değişkenler ise kadın ve erkek eşin evlilik doyumudur (Y). Ayrıca, çocuk sayısı modele kontrol değişkeni olarak eklenmiştir. Modelde ilk olarak bağımsız değişkenlerden (bağlanma boyutları) aracı (evlilik gücü) ve bağımlı (evlilik doyumu) değişkenlere giden tüm yollar ve aracı değişkenlerden bağımlı değişkenlere giden tüm yollar tanımlanmıştır. Kontrol değişkenlerinden aracı değişkenlere ve bağımlı değişkenlere giden yollar da modele eklenmiştir. Ayrıca bağımsız değişkenler arasındaki ilişkiler, kontrol değişkeni ile bağımsız değişkenler arasındaki ilişkiler, aracı değişkenlerin hataları arasındaki ilişkiler ve bağımlı değişkenlerin hataları arasındaki ilişkiler de modele eklenmiştir. Elde edilen bu model ki-karenin serbestlik derecesinin sıfıra eşit olduğu doygun modeldir. Ledermann ve arkadaşlarının (2011) önerileri doğrultusunda doğrudan etkilerin anlamlılığı bu model üzerinden değerlendirilmiştir. Sonrasında modeli sadeleştirmek ve modelin veriye uyumunu test etmek amaciyla anlamsız yollar 


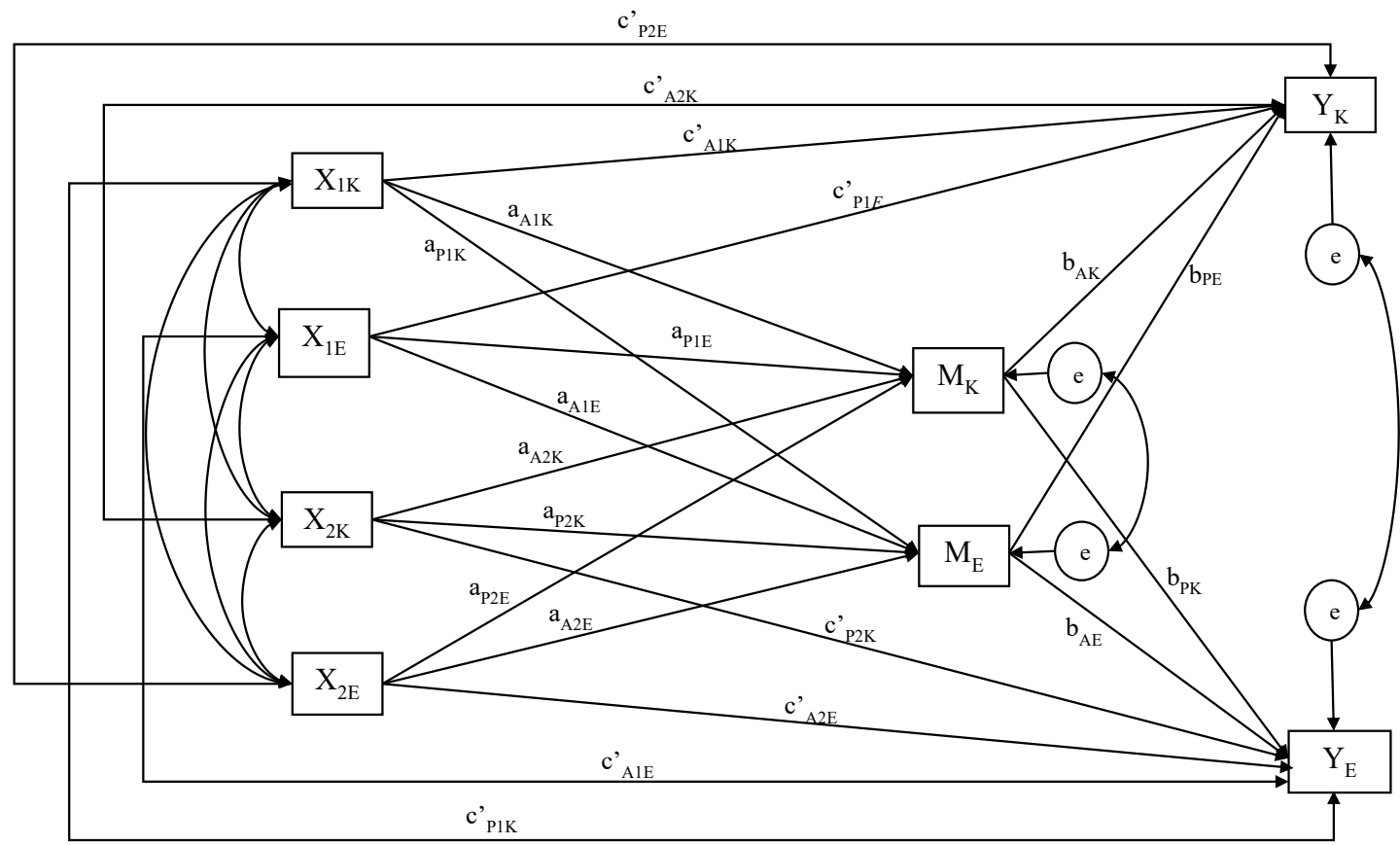

Not 1. X1, bağlanma kaygısını; X2, bağlanma kaçınmasını; M, evlilik gücünü; Y evlilik doyumunu, K, kadın eşi; E, erkek eşi; A, aktör etkisini; P, partner etkisini; e, hata terimini; a, b ve c' aracı değişkenli modellerdeki geleneksel yolları temsil etmektedir. Modeldeki yollar bu kısaltmalara dayanılarak isimlendirilmiştir.

Not 2. Çocuk sayısı kontrol değişkenidir. Anlatım kolaylığı açısından bu değiş̧ken şekilde gösterilmemiştir.

Not 3. Model Ledermann, Macho ve Kenny'den (2011) uyarlanmıştır.

Şekil 1. Bağlanma Boyutları ile Evlilik Doyumu Arasındaki İlişkide Evlilik Gücünün Aracı Rolünün İncelendiği A-APKM.

$(p>.05)$ modelden çıkarılmış ve sadeleştirilmiş model üzerinden aracı etkilerin anlamlılığ 1 test edilmiştir. Bu çalışmada modelin veriye uyumunun değerlendirilmesi amaciyla $\chi^{2}$, CFI, GFI, AGFI, TLI ve RMSEA değerleri incelenmiştir. İstatistiksel olarak anlamlı olmayan bir $\chi^{2}$ değeri, 2'den küçük bir $\chi^{2} /$ sd oran1, .95 'in üzerindeki CFI, GFI, AGFI ve TLI değerleri ve .06'nın altındaki bir RMSEA değeri modelin veriye uyumunun iyi olduğuna işaret etmektedir (Schreiber, 2008).

Analiz sonuçlarına ait tüm standardize edilmemiş regresyon katsayıları $(B)$, standart hatalar $(S H)$ ve $p$ değerleri Tablo 2'de verilmiştir. Tablo 2'den incelenebileceği gibi bağlanma kaygısının evlilik gücü üzerindeki etkisi açısından, hem kadının hem de erkeğin aktör etkilerinin istatistiksel olarak anlamlı olduğu fakat partner etkilerinin istatistiksel olarak anlamlı olmadığı görülmüştür. Buna göre, beklendiği gibi, bağlanma kaygısı arttıkça bireylerin evliliklerinde eşlerine yönelik alg1ladıkları güç azalmaktadır. Ancak, bireylerin bağlanma kaysının eşlerinin evlilik gücünü yordamadığı anlaşılmaktadır. Bağlanma kaçınmasının evlilik gücü üzerindeki etkisi açısından erkeğin aktör etkisinin anlamlı oldu- ğu, erkeğin partner etkisi ve kadının hem aktör hem de partner etkilerinin anlamlı olmadığı görülmüştür. Diğer bir ifadeyle, erkeğin bağlanma kaçınmasının kendisinin evlilik gücünü azaltma eğiliminde olduğu, ancak eşinin evlilik gücünü yordamadığı görülmektedir. Kadın eşin bağlanma kaçınması ise ne kendisinin ne de eşinin evlilik gücünü yordamaktadır.

Evlilik gücünün evlilik doyumu üzerindeki etkisi açısından değerlendirildiğinde hem kadın hem de erkeğin aktör etkilerinin anlamlı olduğu, ancak ne kadının ne de erkeğin partner etkilerinin anlamlı olduğu bulunmuştur. Buna göre, hem kadında hem de erkekte evlilik gücü arttıkça kendilerinin evlilikten aldıkları doyumun yükselme eğiliminde olduğu görülmüştür. Ancak, ne kadının ne de erkeğin evlilik gücünün eşlerinin evlilikten aldıkları doyum üzerinde anlamlı düzeyde etkili olduğu anlaşılmaktadır. Bulgular ayrıca, modeldeki diğer değişkenlerin etkisi kontrol edildikten sonra, bağlanma kaçınmasının, hem kadınlarda hem de erkeklerde, bireyin kendi evlilik doyumunu olumsuz yönde yordadığını, eşin evlilik doyumunu ise anlamlı olarak yordamadığını göstermiştir. Bağlanma kaygısı ise, modeldeki diğer değiş- 
Tablo 2. Bağlanma Boyutları ile Evlilik Doyumu Arasındaki İlişkide Evlilik GücününAracı Rolünün İncelendiğiA-APKM'ye ait Sonuçlar

\begin{tabular}{|c|c|c|c|}
\hline Etki & $B$ & SH & $p$ \\
\hline \multicolumn{4}{|c|}{ Bağlanma Kaygısı $\left(\mathbf{X}_{1}\right) \rightarrow$ Evlilik Gücü $(M)$} \\
\hline Kadın Eşin Aktör Etkisi $\left(\mathrm{a}_{\mathrm{A} 1 \mathrm{~K}}\right)$ &.- .33 & .06 & $<.001$ \\
\hline Erkek Eşin Aktör Etkisi $\left(\mathrm{a}_{\mathrm{AlE}}\right)$ & -.24 & .07 & $<.001$ \\
\hline Kadın Eşin Partner Etkisi $\left(\mathrm{a}_{\mathrm{P} 1 \mathrm{~K}}\right)$ & -.11 & .06 & .07 \\
\hline Erkek Eşin Partner Etkisi $\left(\mathrm{a}_{\mathrm{PIE}}\right)$ & -.01 & .07 & .91 \\
\hline \multicolumn{4}{|c|}{ Bağlanma Kaçınması $\left(\mathrm{X}_{2}\right) \rightarrow$ Evlilik Gücü $(\mathbf{M})$} \\
\hline Kadın Eşin Aktör Etkisi $\left(\mathrm{a}_{\mathrm{A} 2 \mathrm{~K}}\right)$ & -.07 & .06 & .25 \\
\hline Erkek Eşin Aktör Etkisi $\left(\mathrm{a}_{\mathrm{A} 2 \mathrm{E}}\right)$ & -.18 & .07 & .01 \\
\hline Kadın Eşin Partner Etkisi $\left(\mathrm{a}_{\mathrm{P} 2 \mathrm{~K}}\right)$ & .06 & .06 & .37 \\
\hline Erkek Eşin Partner Etkisi $\left(\mathrm{a}_{\mathrm{P} 2 \mathrm{E}}\right)$ & -.01 & .07 & .90 \\
\hline \multicolumn{4}{|c|}{ Evlilik Gücü (M) $\rightarrow$ Evlilik Doyumu (Y) } \\
\hline Kadın Eşin Aktör Etkisi $\left(\mathrm{b}_{\mathrm{AK}}\right)$ & .58 & .15 & $<.001$ \\
\hline Erkek Eşin Aktör Etkisi $\left(\mathrm{b}_{\mathrm{AE}}\right)$ & .37 & .14 & .01 \\
\hline Kadın Eşin Partner Etkisi $\left(\mathrm{b}_{\mathrm{PK}}\right)$ & .11 & .13 & .39 \\
\hline Erkek Eşin Partner Etkisi $\left(\mathrm{b}_{\mathrm{PE}}\right)$ & .28 & .16 & .07 \\
\hline \multicolumn{4}{|c|}{ Bağlanma Kaygısı $\left(\mathrm{X}_{1}\right) \rightarrow$ Evlilik Doyumu $(\mathrm{Y})$} \\
\hline Kadın Eşin Aktör Etkisi (c' $\left.{ }_{\mathrm{AIK}}\right)$ & -.15 & .12 & .21 \\
\hline Erkek Eşin Aktör Etkisi (c' $\left.{ }_{\mathrm{AlE}}\right)$ & .07 & .11 & .55 \\
\hline Kadın Eşin Partner Etkisi ( $\left.{ }^{\prime}{ }_{\mathrm{P} 1 \mathrm{~K}}\right)$ & -.22 & .11 & .04 \\
\hline Erkek Eşin Partner Etkisi ( $\mathrm{c}_{\mathrm{PIE}}$ ) & .10 & .13 & .46 \\
\hline \multicolumn{4}{|c|}{ Bağlanma Kaçınması $\left(\mathbf{X}_{2}\right) \rightarrow$ Evlilik Doyumu $(Y)$} \\
\hline Kadın Eşin Aktör Etkisi (c' ${ }_{\mathrm{A} 2 \mathrm{~K}}$ ) & -.46 & .12 & $<.001$ \\
\hline Erkek Eşin Aktör Etkisi (c' ${ }_{\mathrm{A} 2 \mathrm{E}}$ ) & -.61 & .11 & $<.001$ \\
\hline Kadın Eşin Partner Etkisi ( $\left.{ }^{\prime}{ }_{\mathrm{P} 2 \mathrm{~K}}\right)$ & .04 & .10 & .67 \\
\hline Erkek Eşin Partner Etkisi ( $\left.{ }^{\prime}{ }_{\mathrm{P} 2 \mathrm{E}}\right)$ & .06 & .13 & .67 \\
\hline
\end{tabular}

Not 1. İstatistiksel olarak anlamlı olan regresyon katsayıları vurgulanmıştır.

Not 2. Standardize edilmemiş regresyon katsayıları $(B)$, standart hatalar $(\mathrm{SH})$ ve $p$ değerleri verilmiştir.

Not 3. Çocuk sayısı kontrol edilmiştir.

kenler kontrol edildikten sonra, yalnızca kadınlarda, eşin evlilik doyumunu olumsuz yönde yordamaktadır. Buna göre, bağlanma kaçınması arttıkça, hem kadınlarda hem de erkeklerde, bireyin kendi evlilik doyumu düşmekte; bağlanma kaygısı arttıkça ise, yalnızca kadınlarda, eşin evlilik doyumu düşmektedir.

Sonrasinda, doğrudan aktör etkilerinin cinsiyete göre (kadın eşin ve erkek eşin) farklılaşıp farklılaşmadığını incelemek amacıyla ki-kare fark testi uygulanmıştır. Bu amaçla, tüm doğrudan aktör etkilerine cinsiyetler arasında eşitlik kısıtlaması uygulanmıştır (eşitlik kısıtlamas1 uygulanan yollar: $\mathrm{a}_{\mathrm{A} 1 \mathrm{~K}}=\mathrm{a}_{\mathrm{A} 1 \mathrm{E}} ; \mathrm{a}_{\mathrm{A} 2 \mathrm{~K}}=\mathrm{a}_{\mathrm{A} 2 \mathrm{E}} ; \mathrm{b}_{\mathrm{AK}}=\mathrm{b}_{\mathrm{AE}}$; $\mathrm{c}^{\prime}{ }_{\mathrm{A} 1 \mathrm{~K}}=\mathrm{c}^{\prime}{ }_{\mathrm{AlE}} ; \mathrm{c}^{\prime}{ }_{\mathrm{A} 2 \mathrm{~K}}=\mathrm{c}^{\prime}{ }_{\mathrm{A} 2 \mathrm{E}}$ ). Sonuçta kisıtlamaların eklendiği modelin veriye uyumunun çok iyi olduğu görülmüş- tür, $\chi^{2}(5)=5.29, p=.38, \chi^{2} / s d=1.06$, CFI $=1.00$, GFI $=.99, \mathrm{AGFI}=.94, \mathrm{TLI}=1.00, \mathrm{RMSEA}=.02, \% 90 \mathrm{GA}$ $[.00, .11]$ görülmüştür. Ayrıca ki-kare fark testi sonuçlar1 kisitlamaların eklenmesinin modelin veriye uyumunu kötüleştirmediğini göstermiştir, $\chi_{\text {fark }}^{2}(5)=5.29, p>.05$. $\mathrm{Bu}$ sonuçlar, aktör etkilerinin cinsiyete göre farklılaşmadığına işaret etmektedir.

Sonrasında aracı ve bağımlı değişkenler üzerindeki aktör ve partner etkilerinin eşit olup olmadığının test edilmesi için aracı ve bağımlı değişkenler üzerindeki aktör ve partner etkilerine eşitlik kısıtlaması uygulanarak (eşitlik kısıtlaması uygulanan yollar: $\mathrm{a}_{\mathrm{AIK}}=\mathrm{a}_{\mathrm{PIE}} ; \mathrm{a}_{\mathrm{AIE}}=$ $a_{P 1 K} ; a_{A 2 K}=a_{P 2 E} ; a_{A 2 E}=a_{P 2 K} ; b_{A K}=b_{P E} ; b_{A E}=b_{P K} ; c^{\prime}{ }_{A 1 K}=$ $\mathrm{c}_{\mathrm{PIE}}^{\prime} ; \mathrm{c}^{\prime}{ }_{\mathrm{AlE}}=\mathrm{c}_{\mathrm{P} 1 \mathrm{~K}} ; \mathrm{c}^{\prime}{ }_{\mathrm{A} 2 \mathrm{~K}}=\mathrm{c}_{\mathrm{P} 2 \mathrm{E}} ; \mathrm{c}^{\prime}{ }_{\mathrm{A} 2 \mathrm{E}}=\mathrm{c}_{\mathrm{P} 2 \mathrm{~K}}$ ) ki-kare fark 


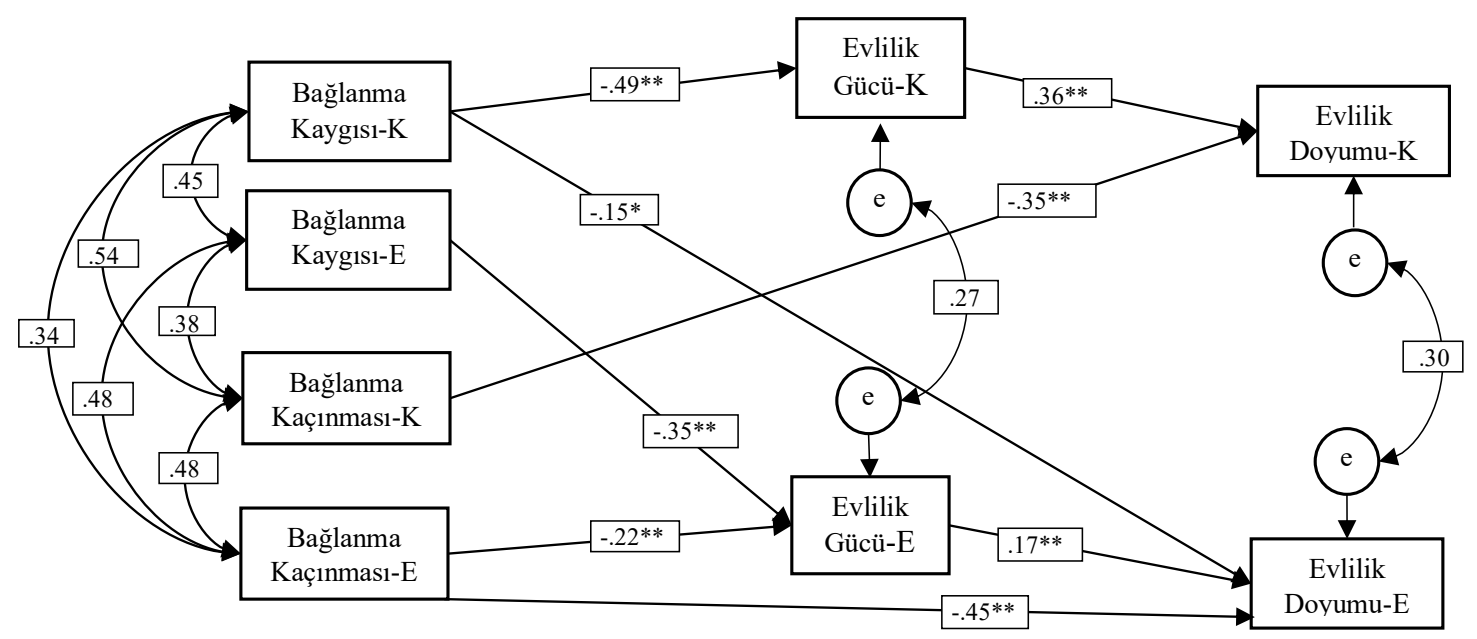

Not 1. K, Kadın eși; E, erkek eși; e, hata terimini ifade etmektedir.

Not 2. Modeli sadeleştirmek amacıyla istatistiksel olarak anlamlı olmayan yollar modelden çıkarılmıştır. Kontrol değişkeninden bağımlı ve aracı değişkenlere giden tüm yollar anlamsız olduğu için kontrol değişkeni modelden çıkarılmıştır. Beta değerleri verilmiştir.

Not $3 . * p<.05 ; * * p<.01$.

Not 4. $\chi^{2}(12)=14.26, p=.28, \chi^{2} / s d=1.19, \mathrm{CFI}=1.00, \mathrm{RMSEA}=.03$.

Şekil 2. Bağlanma Boyutlarının (Bağlanma Kaygısı ve Kaçınması) Bağımsız, Evlilik Gücünün Aracı, Evlilik Doyumunun Bağımlı Değişken, Çocuk Sayısının Kontrol Değişkeni Olduğu A-APKM.

testi yapılmıştır. Sonuçta, bu kısıtlamaların eklendiği modelin veriye uyumunun oldukça kötü olduğu, $\chi^{2}(10)$ $=65.48, p<.001, \chi^{2} / s d=6.55, \mathrm{CFI}=.87, \mathrm{GFI}=.92$, $\mathrm{AGFI}=.62, \mathrm{TLI}=.54, \mathrm{RMSEA}=.19, \% 90 \mathrm{GA}[.14, .23]$ ve kısıtlamaların eklenmesinin modelin veriye uyumunu anlamlı olarak kötüleştirdiği, $\chi_{\text {fark }}^{2}(10)=65.48, p<.05$ bulunmuştur. Bu bulgular aracı ve bağımlı değişkenlerin yordanmasında aktör ve partner etkilerinin eşit olmad1ğını göstermektedir. Özgül olarak, yalnızca kadınlarda, $\chi_{\text {fark }}^{2}(1)=9.14, p<.05$, kişilerin kendi bağlanma kayg1ları, eşlerinin bağlanma kaygılarına göre, kendi evlilik güçlerinin daha güçlü bir yordayıcısıdır. Ayrıca, yalnızca erkeklerde kişilerin kendi bağlanma kaçınması, eşlerinin bağlanma kaçınmasına göre, kendi evlilik güçlerini daha güçlü bir şekilde yordamaktadır, $\chi_{\text {fark }}^{2}(1)=4.93, p<.05$. Ek olarak, hem kadınlarda, $\chi_{\text {fark }}^{2}(1)=6.21, p<.05$, hem de erkeklerde, $\chi_{\text {fark }}^{2}(1)=12.95, p<.05$, eşlerinin bağlanma kaçınmasına göre, kişilerin kendi bağlanma kaçınması kendi evlilik doyumları ile daha fazla ilişkilidir.

Sonrasında, modeldeki anlamsız yollar $(p>.05)$ çıkarılarak model sadeleştirilmiştir ve sadeleştirilmiş modelin veriye uyumunun çok iyi olduğu görülmüştür, $\chi^{2}(12)=14.26, p=.28, \chi^{2} / s d=1.19, \mathrm{CFI}=1.00$, GFI $=.98, \mathrm{AGFI}=.93, \mathrm{TLI}=.99, \mathrm{RMSEA}=.03, \% 90 \mathrm{GA}$ $[.00, .09]$. Bu son modele ait standardize edilmiş regresyon katsayıları (beta değerleri) Şekil 2'de sunulmuştur.
Sonrasında, bu sadeleştirilmiş model üzerinden bağlanma boyutları ile evlilik doyumu arasındaki ilişkide evlilik gücünün aracı rolü incelenmiştir. Bir aracı etkinin incelenmesi için hem a (bağımsız değişken $\rightarrow$ aracı değişken) hem de b (aracı değişken $\rightarrow$ bağımlı değişken) yollarının istatistiksel olarak anlamlı olması bir ön koşul olarak değerlendirilmektedir (Baron ve Kenny, 1986; Ledermann ve Macho, 2009). Bu nedenle, bağlanma kaygı ve bağlanma kaçınmasıyla evlilik doyumu arasındaki ilişkide evlilik gücünün aracı rolünün incelenmesi amacıyla istatistiksel olarak anlamlı olan a ve b yolları üzerinde Bootstrap yöntemi ile aracılık analizleri yapılmıştır. $\mathrm{Bu}$ analizlerde 5000 örneklem üzerinden yanl1lık-düzeltilmiş (bias-corrected) güven aralıkları hesaplanmıştır. Sonuçlar, bağlanma kaygısı ile evlilik doyumu arasındaki ilişkide hem kadın, $B=-.25, S H=.07, p<$ $.001, \% 95$ GA $[-.41,-.14]$, hem de erkekler, $B=-.09$, $S H=.05, p=.02, \% 95$ GA [-.23, -.01] için aktör-aktör dolayl1 etkilerinin $\left(\mathrm{X}_{1 \mathrm{~K}} \rightarrow \mathrm{M}_{\mathrm{K}} \rightarrow \mathrm{Y}_{\mathrm{K}}=\mathrm{a}_{\mathrm{AlK}} \mathrm{b}_{\mathrm{AK}}\right.$ ve $\mathrm{X}_{1 \mathrm{E}}$ $\rightarrow \mathrm{M}_{\mathrm{E}} \rightarrow \mathrm{Y}_{\mathrm{E}}=\mathrm{a}_{\mathrm{AlE}} \mathrm{b}_{\mathrm{AE}}$ ) anlamlı olduğunu göstermiştir. Diğer bir ifadeyle, bağlanma kaygısı arttıkça hem kadınlarda hem de erkeklerde bireyin kendisinin evlilik gücü azalmakta bu da kendisinin düşük evlilik doyumu ile sonuçlanmaktadır. Bağlanma kaçınması açısından ise yalnızca erkeğin aktör-aktör dolaylı etkisinin $\left(X_{2 E} \rightarrow M_{E}\right.$ $\rightarrow \mathrm{Y}_{\mathrm{E}}=\mathrm{a}_{\mathrm{A} 2 \mathrm{E}} \mathrm{b}_{\mathrm{AE}}$ ) anlamlı olduğu bulunmuştur, $B=-.05$, 
$S H=.03, p=.01, \% 95$ GA [-.14, -.01]. Buna göre, bağlanma kaçınması yalnızca erkeklerde kendisinin evlilik gücü aracılığıyla, kendisinin evlilik doyumunu düşürme eğilimi göstermektedir.

Sonuçlar genel olarak değerlendirildiğinde, evlilik doyumunu, bağlanma kaygısının hem kadınlarda hem de erkeklerde evlilik gücü aracılığı ile yordadığını; bağlanma kaçınmasının ise kadınlarda doğrudan, erkeklerde ise hem doğrudan hem de evlilik gücü aracıllğı ile yordad1ğını göstermektedir. Ayrıca, bir istisna dışında (kadının bağlanma kaygısının eşinin evlilik doyumu üzerindeki etkisi), partner etkilerinin anlamlı olmadığı ve modelin aktör etkileri ağırlıklı bir model olduğu görülmüştür.

\section{Tartışma}

$\mathrm{Bu}$ araştırmanın temel amacı, evli çiftlerde bağlanma boyutlarının evlilik doyumu üzerindeki etkisinin ve bu etkide evlilik gücünün aracı rolünün incelenmesiydi. Bağlanma kaygısı ve kaçınmasının bireyin hem kendisinin hem de eşinin evlilik doyumunu düşürmesi ve yüksek bağlanma kaygı ve kaçınması sonucu algılanan düşük gücün bu ilişkilerde aracı rol üstlenmesi beklenmekteydi. Bulgular, bu beklentileri kismen desteklemiştir.

İlk olarak, bağlanma kaçınmasının evlilik doyumunu kadınlarda yalnızca doğrudan, erkeklerde ise hem doğrudan hem de düşük evlilik gücü aracılığ 1 ile yordadığı bulunmuştur. Bağlanma kaçınmasının evlilik doyumu üzerindeki doğrudan etkisi önceki çalışmalarla uyumludur (örn., Harma ve Sümer, 2016; Li ve Chan, 2012). Bununla birlikte, kaygılı bağlanmanın evlilik doyumunu ne erkeklerde ne de kadınlarda doğrudan yordamadığı, hem erkeklerde hem de kadınlarda yalnızca düşük evlilik gücü aracılığıyla düşük evlilik doyumunu yordadığı bulunmuştur. Harma ve Sümer (2016) bağlanma kaçınmasının toplulukçu kültürler için bağlanma kaygısına göre daha büyük risk faktörü olduğunu, çünkü bu kültürlerde bireylerden ilişkilerinde yakınlık kurmaları ve uyumlu olmalarının beklendiğini belirtmektedirler. Aksine, eşe yapışma gibi davranışsal özelliklere sahip kaygılı bağlanma bu toplumlarda batılı toplumlarda olduğu kadar anormal karşıllanmayabilir. Bu nedenle de, kaygıll bağlanma evlilik doyumunu düşürmeyebilir. Harma ve Sümer (2016) bu önerilerini doğrulayacak şekilde, toplulukçu özelliklere de sahip Türkiye'de kaçınmacı bağlanmanın evlilik doyumunu güçlü bir şekilde yordadığını, fakat kaygılı bağlanmanın evlilik doyumunu yordamadığını bulmuşlardır. Türkiye'de yürütülen mevcut çalışmanın bulguları da Harma ve Sümer'in (2016) bulguları ile tutarlıdır.

Bununla birlikte, bağlanma kaygısının evlilik doyumunu doğrudan yordamaması, onun evlilik doyumu üzerinde etkili olmadığı anlamına gelmemektedir. Ça- lışmanın bulgularına göre, kaygılı bağlanma hem kadınlarda hem de erkeklerde evlilik gücü üzerinden evlilik doyumunu yordamaktadır. Buna göre, kaygılı bağlanma düzeyi yüksek bireyler evliliklerinde kendilerini daha güçsüz algılamakta ve bu düşük güç algısı da düşük evlilik doyumunu yordamaktadır. Mikulincer ve Shaver'a (2007) göre de bağlanma kaygısı yüksek bireyler ilişkilerinde eşlerinin dikkatini çekebilmek için hiperaktifleştirici (hyperactivating) stratejileri kullanırlar ve bu da onların ilişkilerinde doyumsuzluk yaşamalarına neden olur. Buna göre, bu bireyler ilişkileriyle aşırı meşguldürler, reddedilmeye ve eşlerinin tepkisizliğine duyarlılıkları çok yüksektir ve eşlerine karşı incinebilirliklerini, yardımsızlıklarını ve muhtaç olma durumlarını abartma eğilimindedirler. Bir eşin bireyin ihtiyaçlarına karşı sürekli hazır bir şekilde beklemesi mümkün olmadığı için, bu bireylerin normal ilişkilerde bile eşlerini daha tepkisiz ve ilgisiz algılama ihtimalleri yüksektir (Mikulincer ve Shaver, 2007). Bu stratejilerin kullanımı ise bireylerin ilişkilerinden düşük doyum almalarına neden olabilir. Eşlerinin onları reddetme durumlarına aşırı duyarlı olan bağlanma kaygısı yüksek bireylerin eşlerini etkileyemedikleri durumları algılamakta da daha seçici oldukları ve evliliklerindeki güçsüzlük durumlarına abartılı bir şekilde duyarlı oldukları söylenebilir. Ayrıca, bir eşin bireyin bütün isteklerini yerine getirebilmesi neredeyse imkânsız olduğundan, eşlerini etkileyemedikleri durumlara daha duyarlı olduğu düşünülen bağlanma kaygısı yüksek bireylerin, eşlerine karşı kendilerini daha güçsüz algılamaları beklenebilir. Ek olarak, bu bireylerin kendilerini evliliklerinde güçsüz ve muhtaç göstererek eşlerinin dikkatini çekmeye çalıştıkları ileri sürülebilir. Buradan yola çıkarak evlilikte güçsüzlük algısının da kaygılı bağlanma örüntüsüne sahip bireylerin evliliklerinde eşlerine karşı kullandıkları bir hiperaktifleştirici strateji olduğu ileri sürülebilir. $\mathrm{Bu}$ da, kaygılı bağlanan bireylerin evliliklerinden daha düşük doyum almalarına yol açabilir. Bir başka deyişle, mevcut çalışmada, bağlanma kaygısının evlilik doyumunu etkileme süreçlerinden biri ortaya çıkarılmıştır. Bu süreç, ilk defa mevcut çalışmada test edildiği için alanyazına önemli bir katkının sağlandığı düşünülmektedir. Ayrıca, bu bulguların kaygılı bağlanma sorunu yaşayan çiftlerle çalışan evlilik terapistlerine de yol gösterici olacağı düşünülmektedir. Diğer bir ifadeyle, bu bulgular, bağlanma kaygısının evlilik doyumu üzerindeki olumsuz etkilerini inceleyen evlilik terapistlerinin çiftlerin evliliklerinde kendilerini ne kadar güçsüz algıladıklarına da odaklanmalarının yararlı olabileceğine işaret etmektedir.

Mevcut çalışmada ayrıca, bağlanma kaçınmasının da evlilik doyumunu evlilik gücü aracılığıyla yordaması beklenmekteydi. Ancak, bu beklenti yalnızca erkekler açısından doğrulanmıştır. Buna göre, erkek katılımcılar- 
da bağlanma kaçınması arttıkça evlilikte algılanan güç azalmakta bu da düşük evlilik doyumuyla sonuçlanmaktadır. Kadınlarda ise, bu ilişkide evlilik gücünün anlamlı bir aracılık etkisi bulunmamıştır. $\mathrm{Bu}$ cinsiyet farklıl1ğının bir nedeni, bağlanma kaçınmasının evlilik gücü üzerindeki etkisinin erkeklerde anlamlı olmasına karşın kadınlarda anlamlı olmamasıdır. Diğer bir ifadeyle, bağlanma kaçınması arttıkça erkeklerde evlilik gücü azalma eğilimi gösterirken, kadınlarda bu ilişki anlamlı değildir. Bu cinsiyet farklılığı güce toplumsal cinsiyet rolleri açısından yüklenmiş anlamdan kaynaklanıyor olabilir. Bununla ilgili olarak, güçlü olmanın erkeklik açısından merkezi bir değere sahip olduğu, güçsüz olmanın ise erkeklik için bir tehdit olduğu ifade edilmektedir (Overall, Hammond, McNulty ve Finkel, 2016). Bu durum, bir yandan eşlerine yakınlık kuramayan ve eşlerinden uzak duran kaçınmacı erkeklerin (Mikulincer ve Shaver, 2007) eşlerinden uzak durmaları nedeniyle, eşlerini yeterince kontrol edememeleri sonucu kendilerini daha güçsüz algılamalarıyla sonuçlanmış olabilir. Diğer bir ifadeyle, kaçınmacı erkekler bir taraftan güçlü olmak isterken diğer taraftan eşlerini etkileyebilecek yakınlığa sahip olmadıkları için kendilerini güçsüz algılıyor olabilirler. Bu da onların evliliklerinden daha düşük doyum almalarına neden olabilir. Kadınlardan eşe göre yüksek güce sahip olmak beklenmediği için, kaçınmacı bağlanma düzeyi yüksek kadınların erkeklerde olduğu gibi bir çatışma yaşamadığı ileri sürülebilir. Çalışmamızdaki ortaya çıkan bu cinsiyet farklılığı toplumsal cinsiyet rollerinin kaçınmacı bağlanma ile evlilik gücü arasındaki ilişkiyi etkileyebileceğini göstermektedir. Bununla birlikte, bu ilişkinin ileriki çalışmalarda daha ayrıntılı olarak incelenmesi önerilmektedir.

Ek olarak, çalışmamızda bağlanma kaygı ve kaçınmasının eşin evlilik doyumunu da düşürmesi ve bu etkide evlilik gücünün aracılık etmesi beklenmekteydi. Ancak, çalışmamızda yalnızca kadının bağlanma kaygısının eşinin evlilik doyumunu olumsuz yönde yordadığg1, diğer partner etkilerinin ise anlamlı olmadığı bulunmuştur. Buna göre, kadının bağlanma kaygısı arttıç̧a eşinin evlilikten aldığ1 doyumun azaldığ $\breve{g}_{1}$ anlaşılmaktadır. Bununla birlikte, erkeğin bağlanma kaygısı eşinin evlilik doyumunu anlamlı bir düzeyde yordamamaktadır. Kaygılı bağlanma ile evlilik doyumu arasındaki ilişkideki benzer cinsiyet farklılıkları diğer çalışmalarda da (Collins ve Read, 1990; Simpson, 1990) bildirilmektedir. Simpson (1990) bu durumu kadının sahiplenici tavrının eşinin doyumunu düşürmesine rağmen, erkeğin sahiplenici tavrının eşinin doyumunu düşürmemesi olarak açıklamaktadır. Buna göre, kaygılı bağlanan kadınların yüksek düzeydeki sahiplenici tavırları eşleri tarafından olumsuz karşılanıp onların evliliklerinden düşük doyum almasıyla sonuçlanırken, kaygılı bağlanan erkeklerin eşlerine karşı sahiplenici tavırları eşlerini rahatsız etmiyor olabilir. Ayrıca, kadının bağlanma kaygısının erkeğin evlilik doyumunu düşürmesi cinsiyetler arasındaki özerklik ihtiyacındaki farktan da kaynaklanıyor olabilir. Mikulincer ve Shaver'a (2007) göre erkeklerin evliliklerinden doyum alabilmeleri için kadınlardan farklı olarak özerklik ihtiyaçlarının giderilmesi gerekir. Ancak, bağlanma kaygısı yüksek olan bir kadınla evlendiklerinde bu ihtiyaçları karşılanmadığı için evliliklerinden aldıkları doyum da düşebilir. Sonuçta, kadının bağlanma kaygısının eşin düşük doyumu için bir risk faktörü olduğu, fakat erkeğin bağlanma kaygısının eşin düşük doyumu ile sonuçlanmadiğı anlaşılmaktadır.

Bununla birlikte, modeldeki diğer partner etkilerinin anlamlı olmadığı görülmüştür. Bu durum, modelde aktör etkilerinin daha baskın olduğunu ve kişinin bağlanma kaygı ve kaçınmasının eşininkinden daha çok kendisinin evlilik gücü ve evlilik doyumu üzerinde etkili olduğunu göstermektedir. Çiftlerle yürütülen önceki çalişmalar da (örn., Molero, Shaver, Fernández ve Recio, 2017), özellikle öz bildirim ölçekleri kullanıldığında, kişinin bağlanma boyutlarının eşininkinden daha çok kişinin kendisinin bağımlı değişkenleri üzerinde etkili olduğuna işaret etmektedir. Bununla birlikte, yine aktör etkileri daha baskın olsa bile, bireyin bağlanma güvensizliğinin eşinin evlilik gücünü (örn., Oka ve ark., 2016) ve evlilik doyumunu (örn., Butzer ve Campbell, 2008) anlamlı bir şekilde düşürdüğünü gösteren çalışmalar da söz konusudur. Önceki çalışmalarda bulunan bu etkilerin çalışmamızda tekrar edilememesinin bir nedeni, çalışmamızın bahsedilen önceki çalışmalara göre daha küçük bir örnekleme sahip olması ve dolayısıyla istatistiksel gücünün daha düşük olması olabilir. İleriki çalışmalarda, bu çalışmada öne sürülen modelin daha büyük bir örneklemle yürütülmesi ve bu etkilerin tekrar test edilmesi, daha sağlıklı sonuçların elde edilmesine katkı sağlayacaktır.

\section{Sınırlılıklar ve Sonuç}

$\mathrm{Bu}$ çalışmanın bazı sınırlılıkları da vardır. İlk olarak çalışmamız ilişkisel bir çalışmadır ve bu durum değişkenler arasında nedensel bir ilişki kurulmasını engellemektedir. Ayrıca çalışmamızda kuramsal çerçeve doğrultusunda bağlanma boyutlarının bağımsız, evlilik gücünün aracı ve evlilik doyumunun bağımlı değişken olduğu düşünülmüştür. Ancak, çalışmamızda bu değişkenler aynı anda ölçüldüğü için zamansal bir sıralama kestirilememektedir. Örneğin, evlilik gücü evlilik doyumunu yordamaktadır ancak evlilik doyumunun evlilik gücünü yordaması da olasıdır. İleride yapılacak boylamsal çalışmalarla bu konu hakkında daha kesin bilgiler edinilebilir. Ayrıca çalışmamıza katılan bireylerin önceki ilişki sayıları, daha önce bir evlilik geçirip geçirmedikle- 
ri gibi ilişkisel öykülerine ilişkin sorular araştırmamızda yer almamıştır. İleriki çalışmalarda bu bilgilerin ölçüldüğü ve kontrol edildiği daha temsil edici çalışmalar yürütülebilir. Ayrıca çalışmamızda evlilik gücü önceki çalışmalarda olduğu gibi (örn., Oka ve ark., 2016) tek boyutlu olarak değerlendirilmiştir. İleriki çalışmalarda evlilik gücü iki boyutlu olarak değerlendirilerek bağlanma boyutlarının güç sonuçları ve güç süreçleri ile ilişkisi daha ayrıntılı olarak değerlendirilebilir.

Sonuç olarak, çalışmamızda bağlanma kaçınmasının evlilik doyumu üzerindeki etkisi açısından önceki çalışmaların bulguları tekrarlanmakla birlikte, evlilik gücünün bağlanma boyutları ile evlilik doyumu arasındaki ilişkide önemli bir rol üstlendiği bulunmuştur. Özellikle bağlanma kaygısının evlilikte algılanan düşük güç aracılığıyla bireyin evlilik doyumunu düşürdüğü bulunmuştur. Ayrıca erkekler için bağlanma kaçınmasının da düşük evlilik gücü ve dolayısıyla düşük evlilik doyumu açısından bir risk faktörü olduğu bulunmuştur.

\section{Kaynaklar}

Ainsworth, M. D. S., Bleher, M. C., Waters, E. ve Wall, S. (1978). Patterns of attachment: A psychological study of the strange stiuation. Hillsdale, NJ: Erlbaum.

Anderson, C. ve Berdahl, J. L. (2002). The experience of power: Examining the effects of power on approach and inhibition tendencies. Journal of Personality and Social Psychology, 83(6), 1362-1377. doi: 10.1037//0022-3514.83.6.1362

Baldwin, M. W., Fehr, B., Keedian, E., Seidel, M. ve Thomson, D. W. (1993). An exploration of the relational schemata underlying attachment styles: Self-report and lexical decision approaches. Personality and Social Psychology Bulletin, 19(6), 746-754. doi: 10.1177/0146167293196010

Ball, J., Cowan, P. ve Cowan, C. (1995). Who's got the power? Gender differences in partners' perceptions of influence during marital problem-solving discussions. Family Process, 34(3), 303-321. doi: 10.1111/j.1545-5300.1995.00303.x

Babcock, J. C., Waltz, J., Jacobson, N. S. ve Gottman, J. M. (1993). Power and violence: The relation between communication patterns, power discrepancies, and domestic violence. Journal of Consulting and Clinical Psychology, 61(1), 40-50. doi: 10.1037//0022-006x.61.1.40

Baron, R. M. ve Kenny, D. A. (1986). The moderatormediator variable distinction in social psychological research: Conceptual, strategic, and statistical considerations. Journal of Personality and Social Psychology, 51(6), 1173-1182. doi: 10.1037//00223514.51.6.1173

Brassard, A., Lussier, Y. ve Shaver, P. R. (2009). Attachment, perceived conflict, and couple satisfaction: Test of a mediational dyadic model. Family Relations: An Interdisciplinary Journal of Applied Family Studies, 58(5), 634-646. doi: 10.1111/j.17413729.2009.00580.x

Boon, S. D. ve Griffin, D. W. (1996). The construction of risk in relationships: The role of framing in decisions about intimate relationships. Personal Relationships, 3(3), 293-306. doi: 10.1111/j.14756811.1996.tb00118.x

Bowlby, J. (1969). Attachment and loss: Attachment. New York: Basic Books.

Bowlby, J. (1973). Attachment and loss: Separation, anxiety and anger. New York: Basic Books.

Brennan, K. A., Clarck, C. L. ve Shaver, P. R. (1998). Self-report measurement of adult attachment: An integrative overview. J. A. Simpson ve W. S. Rholes (Ed.), Attachment theory and close relationships 
içinde (s. 46-76). New York: Guilford Press.

Brezsnyak, M. ve Whisman, M. A. (2004). Sexual desire and relationship functioning: The effects of marital satisfaction and power. Journal of Sex \& Marital Therapy, 30(3), 199-217. doi: $10.1080 / 00926230490262393$

Butzer, B. ve Campbell, L. (2008). Adult attachment, sexual satisfaction, and relationship satisfaction: A study of married couples. Personal Relationships, 15(1), 141-154. doi: 10.1111/j.14756811.2007.00189.x

Büyükşahin, A., Hasta, D. ve Hovardaoğlu, S. (2005). İlişki istikrarı ölçeği: Geçerlik ve güvenirlik çalışmas1. Türk Psikoloji Yazıları, 8(16), 25-35.

Byrne, M. ve Carr, A. (2000). Depression and power in mariage. Journal of Family Therapy, 22(4), 408427. doi: 10.1111/1467-6427.00161

Campbell, L., Simpson, J. A., Boldry, J. ve Kashy, D. A. (2005). Perceptions of conflict and support in romantic relationships: The role of attachment anxiety. Journal of Personality and Social PSychology, 88(3), 510-531. doi: 10.1037/00223514.88.3.510

Chung, M. S. (2014). Pathways between attachment and marital satisfaction: The mediating roles of rumination, empathy, and forgiveness. Personality and Individual Differences, 70, 246-251. doi: 10.1016/j.paid.2014.06.032

Collins, N. L. ve Read, S. J. (1990). Adult attachment, working models, and relationship quality in dating couples. Journal of Personality and Social Psychology, 58(4), 644-663. doi: 10.1037//00223514.58.4.644

Cromwell, R. E. ve Olsen, D. H. (Ed.). (1975). Power in Families. Oxford, England: Sage.

Crosbie-Burnett, M. ve Giles-Sims, J. (1991). Marital power in stepfather families: a test of normative-resource theory. Journal of Family Psychology, 4(4), 484-496. doi: 10.1037/0893-3200.4.4.484

Day, R. D., Bean, R., Coyne, S., Dyer, J., Harper, J. ve Walker, L. (2016). The Flourishing Families Project: Survey of Family Life. Brigham Young Üniversitesi.

Davila, J., Bradbury, T. N. ve Fincham, F. (1998). Negative affectivity as a mediator of the association between adult attachment and marital satisfaction. Personal Relationships, 5(4), 467-484. doi: 10.1111/j.1475-6811.1998.tb00183.x

Fraley, R. C. ve Waller, N. G. (1998). Adult attachment patterns: A test of the typological model. J. A. Simpson ve W. S. Rholes (Ed.), Attachment Theory and Close Relationships içinde (s. 77-114). New York: Guilford Press.
Fraley, R. C., Waller, N. G. ve Brennan, K. A. (2000). An item response theory analysis of self-report measures of adult attachment. Journal of Personality and Social Psychology, 78(2), 350-365. doi: 10.1037/0022-3514.78.2.350

Galliher, R. V., Rostosky, S. S., Welsh, D. P. ve Kawaguchi, M. C. (1999). Power and psychological well-being in late adolescent romantic relationships. Sex Roles, 40(9-10), 689-710. doi: 10.1023/A:1018804617443

Harma, M. ve Sümer, N. (2016). Are avoidant wives and anxious husbands unhappy in a collectivist context? Dyadic associations in established marriages. Journal of Family Studies, 22(1), 63-79. doi: 10.1080/13229400.2015.1024711

Hazan, C. ve Shaver, P. (1987). Romantic love conceptualized as an attachment process. Journal of Personality and Social Psychology, 52(3), 511-524. doi: 10.1037/0022-3514.52.3.511

Kaynak-Malatyalı, M. K. (2014). Evli çiftlerde algılanan gücün bağlanma boyutlart ve yatırım modeli değişkenleri açısından incelenmesi. Yayınlanmamış yüksek lisans tezi, Ankara Üniversitesi, Ankara.

Kenny, D. A., Kashy, D. A. ve Cook, W. L. (2006). Dyadic data analysis. New York, NY: The Guilford Press.

Kifer, Y., Heller, D., Perunovic, W. Q. E. ve Galinsky, A. D. (2013). The good life of the powerful the experience of power and authenticity enhances subjective well-being. Psychological Science, 24(3), 280-288. doi: 10.1177/0956797612450891

Knobloch, L. K., Solomon, D. H. ve Cruz, M. G. (2001). The role of relationship development and attachment in the experience of romantic jealousy. Personal Relationships, 8(2), 205-224. doi: 10.1111/ j.1475-6811.2001.tb00036.x

Laurenceau, J. P., Kleinman, B. M., Kaczynski, K. J. ve Carver, C. S. (2010). Assessment of relationship-specific incentive and threat sensitivities: Predicting satisfaction and affect in adult intimate relationships. Psychological Assessment, 22(2), 407-419. doi: 10.1037/a0019231

Ledermann, T. ve Macho, S. (2009). Mediation in dyadic data at the level of the dyads: A Structural Equation Modeling approach. Journal of Family Psychology, 23(5), 661-670. doi: 10.1037/a0016197

Ledermann, T., Macho, S. ve Kenny, D. A. (2011). Assessing mediation in dyadic data using the actor-partner interdependence model. Structural Equation Modeling: A Multidisciplinary Journal, 18(4), 595-612. doi: 10.1080/10705511.2011.60709

Lemay, E. P. ve Dudley, K. L. (2009). Implications of reflected appraisals of interpersonal insecurity 
for suspicion and power. Personality and Social Psychology Bulletin, 35(12), 1672-1686. doi: 10.1177/0146167209348380

Li, T. ve Chan, D. K. S. (2012). How anxious and avoidant attachment affect romantic relationship quality differently: A meta-analytic review. European Journal of Social Psychology, 42(4), 406-419. doi: 10.1002/ejsp.1842

Lindahl, K. M., Malik, N. M., Kaczynski, K. ve Simons, J. S. (2004). Couple power dynamics, systemic family functioning, and child adjustment: A test of a mediational model in a multiethnic sample. Development and Psychopathology, 16(3), 609-630. doi: 10.1017/s0954579404004699

Mikulincer, M. ve Shaver, P. R. (2007). Attachment in adulthood: Structure, dynamics, and change. New York: Guilford Press.

Molero, F., Shaver, P., Fernández, I. ve Recio, P. (2017). Attachment insecurities, life satisfaction, and relationship satisfaction from a dyadic perspective: The role of positive and negative affect. European Journal of Social Psychology, 47(3), 337-347. doi: 10.1002/ejsp. 2276

Oka, M., Brown, C. C. ve Miller, R. B. (2016). Attachment and relational aggression: Power as a mediating variable. The American Journal of Family Therapy, 44(1), 24-35. doi: 10.1080/01926187.2015.1105716

Overall, N. C., Hammond, M. D., McNulty, J. K. ve Finkel, E. J. (2016). When power shapes interpersonal behavior: Low relationship power predicts men's aggressive responses to low situational power. Journal of Personality and Social Psychology, 111(2), 195-217. doi: $10.1037 /$ pspi0000059

Özen, A. (2012). Experience and expression of emotions in marital conflict: An attachment theory perspective. Yayınlanmamış Doktora Tezi, Ortadoğu Teknik Üniversitesi, Ankara.

Pistole, M. C., Clark, E. M. ve Tubbs, A. L. (1995). Love relationships: Attachment style and the investment model. Journal of Mental Health Counseling, 17(2), 199-209.

Rogers, W. S., Bidwell, J. ve Wilson, L. (2005). Perception of and satisfaction with relationship power, sex, and attachment styles: A couples level analysis. Journal of Family Violence, 20(4), 241-251. doi: 10.1007/s10896-005-5988-8

Rusbult, C. E., Martz, J. M. ve Agnew, C. R. (1998). The investment model scale: Measuring commitment level, satisfaction level, quality of alternatives, and investment size. Personal Relationships, 5(4), 357-387. doi: 10.1111/j.1475-6811.1998.tb00177.x
Sagrestano, L. M., Heavey, C. L. ve Christensen, A. (1999). Perceived power and physical violence in marital conflict. Journal of Social Issues, 55(1), 65-79. doi: 10.1111/0022-4537.00105

Schmid-Mast, M., Jonas, K. ve Hall, J. A. (2009). Give a person power and he or she will show interpersonal sensitivity: The phenomenon and its why and when. Journal of Personality and Social Psychology, 97(5), 835-850. doi: 10.1037/a0016234

Scheepers, D., de Wit, F., Ellemers, N. ve Sassenberg, K. (2012). Social power makes the heart work more efficiently: Evidence from cardiovascular markers of challenge and threat. Journal of Experimental Social Psychology, 48(1), 371-374. doi: 10.1016/j. jesp.2011.06.014

Schreiber, J. B. (2008). Core reporting practices in structural equation modeling. Research in Social and Administrative Pharmacy, 4(2), 83-97. doi: 10.1016/j.sapharm.2007.04.003

Selçuk, E., Günaydın, G., Sümer, N. ve Uysal, A. (2005). Yetişkin bağlanma boyutları için yeni bir ölçüm: Yakın ilişkilerde yaşantılar envanteri-II'nin Türk örnekleminde psikometrik açıdan değerlendirilmesi. Türk Psikoloji Yazıları, 8(16), 1-11.

Simpson, J. A. (1990). Influence of attachment styles on romantic relationships. Journal of Personality and Social Psychology, 59(5), 971-980. doi: 10.1037/0022-3514.59.5.971

Simpson, J. A., Farrell, A. K., Orina, M. M. ve Rothman, A. J. (2015). Power and social influence in relationships. M. Mikulincer, P. R. Shaver, J. A. Simpson ve J. F. Dovidio (Ed.), APA Handbook of Personality and Social Psychology, Vol. 3: Interpersonal Relations içinde (s. 393-420). Washington, DC: APA Press.

Zimbler, M. S. (2012). Newlywed couples' marital satisfaction and patterns of cortisol reactivity and recovery as a response to differential marital power. Yayınlanmamış doktora tezi. University of Massachusetts, Amherst. 


\section{Summary \\ The Mediating Role of Marital Power on the Relationship between Attachment Dimensions and Marital Satisfaction among Married Couples}

\author{
Meryem Kaynak Malatyalı \\ Ankara University
}

Studies have shown that insecure attachment is related to low satisfaction in relationships (e.g., Butzer \& Campbell, 2008; Davila, Bradbury, \& Fincham, 1998; Harma \& Sümer, 2016; Mikulincer \& Shaver, 2007). Specifically, individuals attached to their spouses anxiously or in an avoidant manner were shown to have less marital satisfaction. In addition, it was indicated that spouses married to an insecurely attached person also had lower marital satisfaction (e.g., Butzer \& Campbell, 2008; Harma \& Sümer, 2016). Considering the crucial effect of insecure attachment on marital satisfaction of both partners, it is essential to uncover the underlying mechanisms.

It was repeatedly reported that attachment insecurity was related to perceived low power in relationships (Lemay \& Dudley, 2009; Oka, Brown, \& Miller, 2016) and low power was related to low relationship satisfaction (Brezsnyak \& Whisman, 2004; Kifer, Heller, Perunovic, \& Galinsky, 2013; Zimbler, 2012). Therefore, it can be suggested that marital power mediates the association of attachment anxiety and avoidance with marital satisfaction. However, to the best of our knowledge, the mediating role of marital power on this association has not yet been investigated. In this context, this study aimed to investigate the relationship between attachment insecurity (high attachment anxiety or avoidance) and marital satisfaction and the mediating role of marital power within this relationship. Additionally, we also aimed to understand the association between an individual's attachment insecurity and his/her partner's marital satisfaction and the mediating role of actor's and/or partner's marital power on this association.

\section{Attachment and Marital Satisfaction \\ Satisfaction is defined as 'having needs met, and within long-term couple relationships, the needs have to do with wishes for love, intimacy, affection, accep-}

\author{
Ayda Büyükşahin Sunal \\ Ankara University
}

tance, understanding, support, and security, as well as more individualistic wishes for autonomy, growth, and competence' and it is stated that 'in terms of attachment theory, relationship satisfaction depends on the extent to which partners effectively meet their needs for proximity, a safe haven, and a secure base' (Mikulincer \& Shaver, 2007, p. 308). In addition, attachment anxiety and attachment avoidance were reported to be associated with low marital satisfaction (Mikulincer \& Shaver, 2007). Accordingly, attachment anxiety and attachment avoidance were linked to the couple's nonfunctional reactions given against relationship problems that were common in every marriage, and as a result, they were linked to the couples' dissatisfaction in their marriage. In the present study, attachment anxiety and attachment avoidance were expected to predict an individual's own marital satisfaction (Hypothesis 1) as well as that of his/ her partner's (Hypothesis 2).

The Mediating Role of Marital Power on the Association between Attachment Dimensions and Marital Satisfaction

In accordance with the various definitions presented in the literature, briefly, power can be defined as an individual's ability or potential to influence others' behaviors, gains or resources and change them in order for the individual to attain his/her own goals (see Simpson, Farrell, Orina, \& Rothman, 2015). Numerous studies indicated that attachment insecurity was related to the perceived low power in relationships (e.g., Lemay \& Dudley, 2009; Oka et al., 2016). In the present study, parallel to the findings of previous studies, both attachment anxiety and attachment avoidance were expected to be related to low marital power.

In association with insecure attachment, low relationship power was found to be related to various

Address for Correspondence: Res. Asst. Meryem Kaynak Malatyal1, Ankara University, Faculty of Languages History and Geography, Department of Psychology, No: 45 Sihhiye / Ankara

E-mail: mkaynak@ankara.edu.tr 
Table 1. Descriptive Statistics and Partial Correlations Among Study Variables Controlling for The Number of Children

\begin{tabular}{|c|c|c|c|c|c|c|c|c|}
\hline & 1 & 2 & 3 & 4 & 5 & 6 & 7 & 8 \\
\hline 1. W (Wife) Attachment Anxiety & - & & & & & & & \\
\hline 2. H (Husband) Attachment Anxiety & $.45^{* *}$ & - & & & & & & \\
\hline 3. W Attachment Avoidance & $.54 * *$ & $.39 * *$ & - & & & & & \\
\hline 4. H Attachment Avoidance & $.34 * *$ & $.51 * *$ & $.47 * *$ & - & & & & \\
\hline 5. W Marital Power & $-.51 * *$ & $-.26^{* *}$ & $-.35^{* *}$ & $-.22 * *$ & - & & & \\
\hline 6. H Marital Power & $-.33 * *$ & $-.46^{* *}$ & $-.23 * *$ & $-.40 * *$ & $.38 * *$ & - & & \\
\hline 7. W Marital Satisfaction & $-.43 * *$ & $-.23 * *$ & $-.46 * *$ & $-.24 * *$ & $.49 * *$ & $.32 * *$ & - & \\
\hline 8. H Marital Satisfaction & $-.38 * *$ & $-.35^{* *}$ & $-.31 * *$ & $-.54 * *$ & $.30 * *$ & $.43 * *$ & $.42 * *$ & - \\
\hline Mean & 3.31 & 3.11 & 2.29 & 2.37 & 3.78 & 3.78 & 7.80 & 7.97 \\
\hline Standard Deviation & 1.01 & .90 & .98 & .92 & .74 & .71 & 1.47 & 1.32 \\
\hline
\end{tabular}

Note. $* p<.05 ; * * p<.01$

problems in marriage (e.g., Babcock, Waltz, Jacobson, \& Gottman, 1993; Sagrestano, Heavey, \& Christensen, 1999 ) as well as to low marital and relationship satisfaction (Brezsnyak \& Whisman, 2004; Kifer et al., 2013; Zimbler, 2012). Similarly, in this study, as a result of attachment anxiety and attachment avoidance, perceived low marital power was predicted to create low marital satisfaction among individuals. In other words, both attachment anxiety and attachment avoidance were expected to decrease marital power which in turn was expected to decrease each spouse's marital satisfaction (Hypothesis 3 ). In addition, attachment anxiety and avoidance were expected to negatively predict the spouse's marital satisfaction through the individual's and/or the spouse's low marital power (Hypothesis 4).

\section{Method}

\section{Participants}

Participants of the current study were 164 married couples, reached out through snowball sampling. Two couples were excluded from the study as data from at least one spouse included outliers. Analyses were performed with the remaining 162 couples. The participants were aged between 21 and 54 years $(M=31.44, S D=$ 4.74).

\section{Materials}

Personal Information Form. In this form, the participants were asked to provide personal information such as gender, age, education level, and employment status.

Couple Power Scale. Couple Power Scale which was developed as part of The Flourishing Families Project (Day et al., 2016) was used in the study. The scale was adapted into Turkish by Kaynak-Malatyalı (2014). In the present study, internal consistency was calculated as .85 for husbands and .87 for wives.

Investment Model Scale. The scale was developed by Martz and Agnew (1998). It was adapted into Turkish by Büyükşahin, Hasta and Hovardaoğlu (2005). The relationship satisfaction dimension of the scale was only used in the present study. In this study, internal consistency for relationship satisfaction dimension was found .96 for husbands and .97 for wives.

Experiences in Close Relationships Inventory-Revised. The scale was developed by Waller and Brennan (2000). It has two dimensions namely avoidance and anxiety. The scale was adapted into Turkish by Selçuk, Günaydın, Sümer and Uysal (2005). In the present study, internal consistency for the anxiety dimension was calculated as .83 for husbands and .86 for wives. Internal consistency for avoidance dimension was .87 for husbands and .89 for wives. 


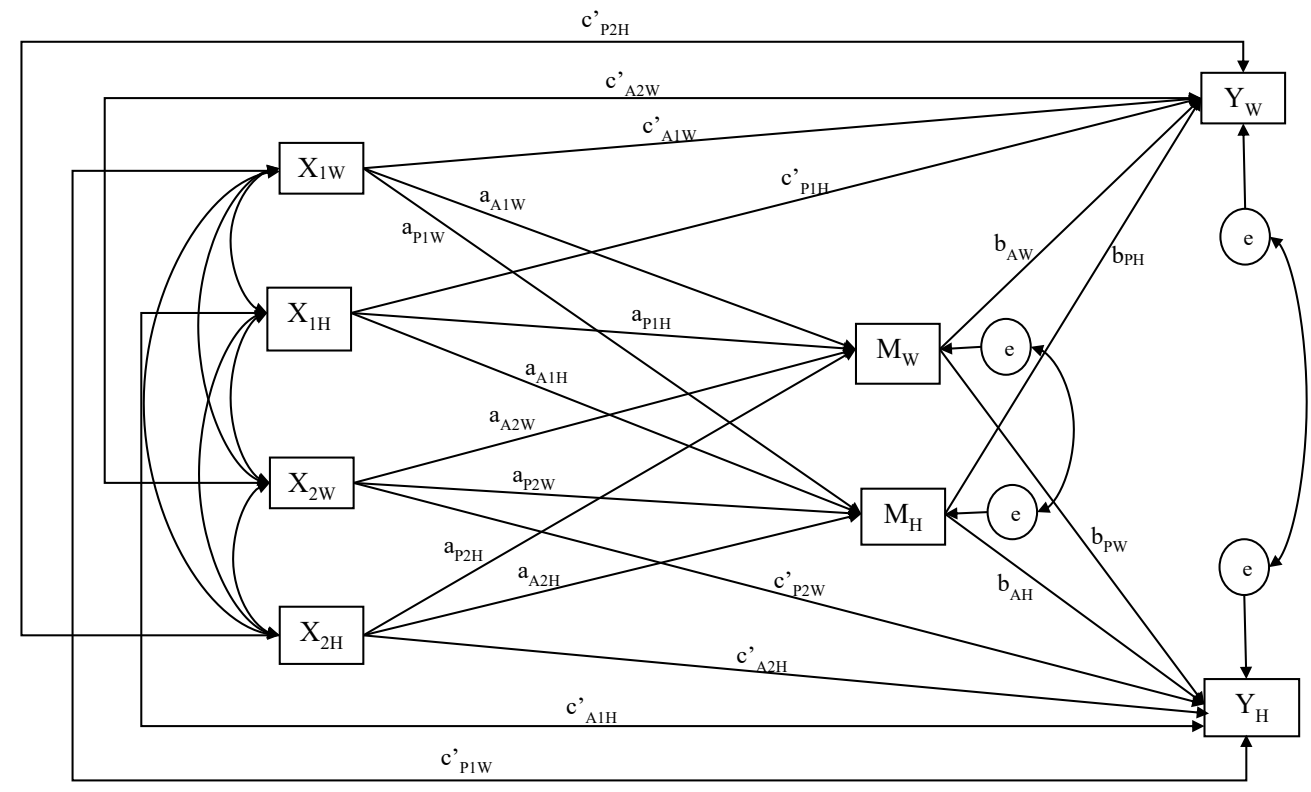

Figure 1. Proposed APIMeM investigating the mediating role of marital power on the association between attachment dimensions (anxiety and avoidance) and marital satisfaction. X1 refers to attachment anxiety; X2 refers to attachment avoidance; $\mathrm{M}$ refers to marital power; $\mathrm{Y}$ refers to marital satisfaction; $\mathrm{W}$ refers to wife; $\mathrm{H}$ refers to husband; A refers to actor effect; P refers to partner effect; e refers to error term; a, b and c' refers to traditional paths in models with mediation. Paths were named according to these abbreviations. The number of children is covariate. Covariate was not shown in the figure to make the figure more understandable. The model was adapted from that of Ledermann, Macho and Kenny (2011).

\section{Procedure}

The scales were provided to the participants in envelopes and the participants delivered them sealed up. The participants were informed about the study in the first page of the form and they were asked to provide their voluntary consent.

\section{Results}

Partial correlations among the main study variables (attachment anxiety, attachment avoidance, marital power and marital satisfaction) were computed after controlling for the number of children (see Table 1). All correlations between the variables were in the expected direction and significant.

Next, in order to investigate the gender differences among the study variables, a series of repeated measures analyses of variance were conducted controlling for the number of children. Results indicated that there were no significant gender differences on attachment avoidance, $F(1,160)=.35, p=.56$; attachment anxiety, $F(1,160)=$ $.92, p=.34$; marital power, $F(1,160)=.23, p=.63$; and marital satisfaction, $F(1,160)=1.91, p=.17$, after controlling for the number of children.
Study hypotheses were tested by using Actor-Partner Interdependence Model with Mediation (APIMeM, Ledermann, Macho, \& Kenny, 2011) in which a pair of mediating variables were added to Actor-Partner Interdependence Model (APIM, Kenny, Kashy, \& Cook, 2006) using AMOS program. The proposed model was presented in Figure 1. In the model, independent variables were husband's and wife's attachment anxiety $\left(X_{1}\right)$ and attachment avoidance $\left(\mathrm{X}_{2}\right)$, mediating variables were husband's and wife's marital power (M), and dependent variables were husband's and wife's marital satisfaction (Y). In addition, the number of children was added as covariate. The final model was the saturated model of which degrees of freedom equal to zero.

All unstandardized regression coefficients $(B)$, standard errors (SE) and $p$ values were shown in Table 2 . In terms of the effect of attachment anxiety on marital power, actor effect of both wives and husbands were found to be statistically significant while partner effects of both wives and husbands were found to be statistically non-significant. As for the effect of attachment avoidance on marital power, actor effect of husbands was significant whereas husbands' partner effect and wives' both actor and partner effects were non-significant. 
Table 2. Unstandardized Regression Coefficients (B), Standard Errors (SE) and $p$ Values for the APIMeM.

\begin{tabular}{|c|c|c|c|}
\hline Effect & $B$ & $S E$ & $p$ \\
\hline \multicolumn{4}{|c|}{ Attachment Anxiety $\left(X_{1}\right) \rightarrow$ Marital Power $(M)$} \\
\hline Wife Actor Effect $\left(\mathrm{a}_{\mathrm{A} 1 \mathrm{~W}}\right)$ & -.33 & .06 & $<.001$ \\
\hline Husband Actor Effect $\left(\mathrm{a}_{\mathrm{A} 1 \mathrm{H}}\right)$ & -.24 & .07 & $<.001$ \\
\hline Wife Partner Effect $\left(\mathrm{a}_{\mathrm{P} 1 \mathrm{~W}}\right)$ & -.11 & .06 & .07 \\
\hline Husband Partner Effect $\left(\mathrm{a}_{\mathrm{P} 1 \mathrm{H}}\right)$ & -.01 & .07 & .91 \\
\hline \multicolumn{4}{|c|}{ Attachment Avoidance $\left(\mathrm{X}_{2}\right) \rightarrow$ Marital Power $(M)$} \\
\hline Wife Actor Effect $\left(\mathrm{a}_{\mathrm{A} 2 \mathrm{~W}}\right)$ & -.07 & .06 & .25 \\
\hline Husband Actor Effect $\left(\mathrm{a}_{\mathrm{A} 2 \mathrm{H}}\right)$ & -.18 & .07 & .01 \\
\hline Wife Partner Effect $\left(\mathrm{a}_{\mathrm{P} 2 \mathrm{~W}}\right)$ & .06 & .06 & .37 \\
\hline Husband Partner Effect $\left(\mathrm{a}_{\mathrm{P} 2 \mathrm{H}}\right)$ & -.01 & .07 & .90 \\
\hline \multicolumn{4}{|c|}{ Marital Power (M) $\rightarrow$ Marital Satisfaction (Y) } \\
\hline Wife Actor Effect $\left(\mathrm{b}_{\mathrm{AW}}\right)$ & .58 & .15 & $<.001$ \\
\hline Husband Actor Effect $\left(\mathrm{b}_{\mathrm{AH}}\right)$ & .37 & .14 & .01 \\
\hline Wife Partner Effect $\left(\mathrm{b}_{\mathrm{PW}}\right)$ & .11 & .13 & .39 \\
\hline Husband Partner Effect $\left(\mathrm{b}_{\mathrm{PH}}\right)$ & .28 & .16 & .07 \\
\hline \multicolumn{4}{|c|}{ Attachment Anxiety $\left(X_{1}\right) \rightarrow$ Marital Satisfaction $(Y)$} \\
\hline Wife Actor Effect $\left(\mathrm{c}_{\mathrm{AlW}}{ }_{\mathrm{W}}\right)$ & -.15 & .12 & .21 \\
\hline Husband Actor Effect $\left(\mathrm{c}_{\mathrm{AlH}}{ }\right)$ & .07 & .11 & .55 \\
\hline Wife Partner Effect ( $\left.\mathrm{c}_{\mathrm{PIW}}\right)$ & -.22 & .11 & .04 \\
\hline Husband Partner Effect $\left(\mathrm{c}_{\mathrm{P} 1 \mathrm{H}}\right)$ & .10 & .13 & .46 \\
\hline \multicolumn{4}{|c|}{ Attachment Avoidance $\left(\mathrm{X}_{2}\right) \rightarrow$ Marital Satisfaction $(\mathrm{Y})$} \\
\hline Wife Actor Effect $\left(\mathrm{c}_{\mathrm{A} 2 \mathrm{~W}}{ }\right)$ & -.46 & .12 & $<.001$ \\
\hline Husband Actor Effect ( $\left.\mathrm{c}_{\mathrm{A} 2 \mathrm{H}}\right)$ & -.61 & .11 & $<.001$ \\
\hline Wife Partner Effect $\left(\mathrm{c}_{\mathrm{P} 2 \mathrm{~W}}^{\prime}\right)$ & .04 & .10 & .67 \\
\hline Husband Partner Effect ( $\left({ }^{\prime}{ }_{\mathrm{P} 2 \mathrm{H}}\right)$ & .06 & .13 & .67 \\
\hline
\end{tabular}

Note. Statistically significant paths were given in bold.

Considering the predicting role of marital power on marital satisfaction, actor effects of both husbands and wives were significant whereas partner effects of neither of the spouses were significant. Findings also indicated that after controlling for the effect of all other variables, for both husbands and wives, attachment avoidance negatively predicts the individual's own marital satisfaction, however attachment avoidance does not significantly predict the spouse's marital satisfaction. Only wives' attachment anxiety negatively predicted the partner's marital satisfaction.

We conducted a chi-square difference test to examine whether direct actor effects are equal across genders. The results indicated that actor effects did not vary according to gender, $\chi_{\text {difference }}^{2}(5)=5.29, p>.05$. Another chi-square difference test was conducted to test whether actor and partner effects on marital power and marital satisfaction are equal. The results revealed that actor and partner effects were not equal in predicting marital power and marital satisfaction, $\chi_{\text {difference }}^{2}(10)=65.48, p<.05$.

Next, the model was simplified by removing non-significant paths (i.e., $p>.05$ ) and it was observed that the simplified model fit the data very well, $\chi^{2}(12)$ $=14.26, p=.28, \chi^{2} / d f=1.19$, CFI $=1.00, \mathrm{GFI}=.98$, AGFI $=.93$, TLI $=.99$, RMSEA $=.03,90 \%$ CI $[.00, .09]$. Standardized regression coefficients (beta values) of this final model were presented in Figure 2. Afterwards, using this simplified model, we examined the mediating role of marital power on the association between attachment dimensions and marital satisfaction. Results showed that 


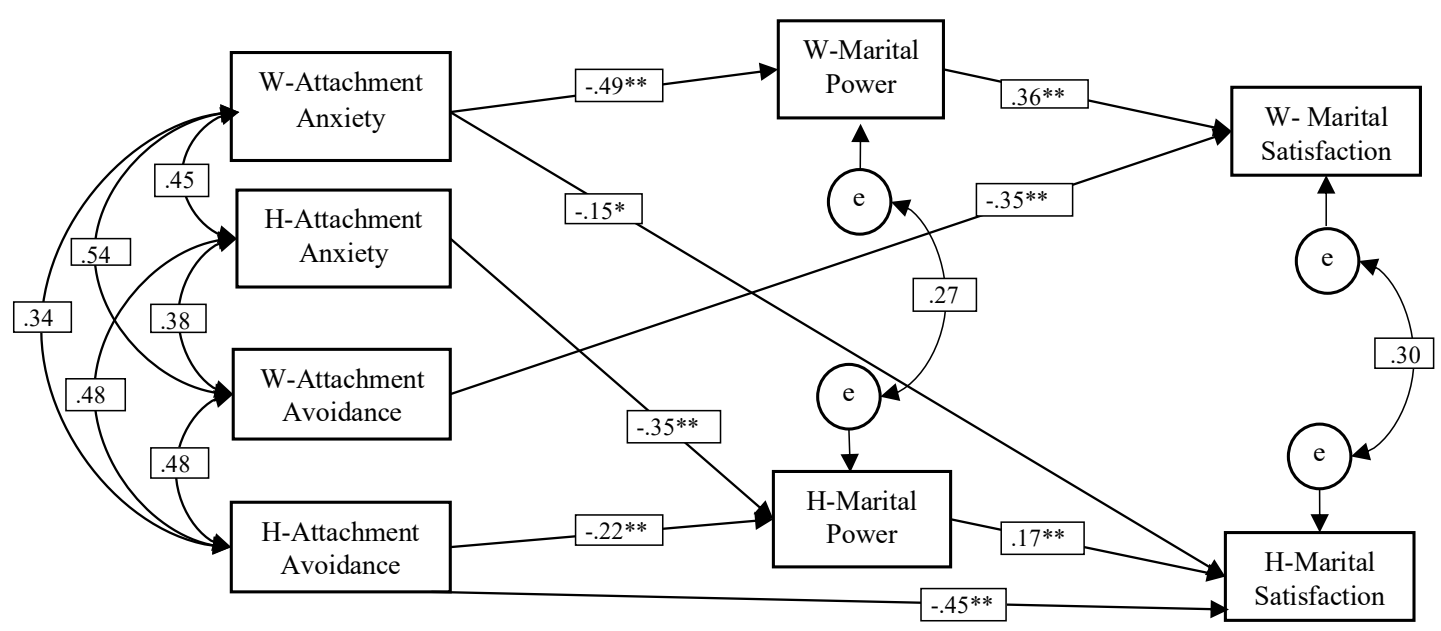

Note. $\chi^{2}(12)=14.26, p=.28, \chi^{2} / \mathrm{df}=1.19, \mathrm{CFI}=1.00, \mathrm{RMSEA}=.03$

Figure 2. APIMeM predicting marital satisfaction. Attachment dimensions (anxiety and avoidance) were independent variables, marital power was mediating variable, marital satisfaction was dependent variable and the number of children was control variable. W refers to wife; $\mathrm{H}$ refers to husband and e refers to error term. Non-significant paths $(p>.05)$ were removed in order to simplify the model. The paths from control variable to mediating and to dependent variables were all non-significant. Therefore, control variable was removed from the model. Standardized regression coefficients (beta) were given. $* p<.05 ; * * p .01$

on the relationship between attachment anxiety and marital satisfaction, actor-actor indirect effects were significant both for wives $B=-.25, S E=.07, p<.001,95 \% \mathrm{CI}$ $[-.41,-.14]$ and for husbands, $B=-.09, S E=.05, p=.02$, $95 \%$ CI $[-.23,-.01]$. In other words, as the attachment anxiety increased, individual's own marital power tended to decrease for both husbands and wives, this in turn tended to decrease individual's own marital satisfaction. In terms of attachment avoidance, it was found that only husband's actor-actor indirect effect was significant, $B=$ $-.05, S E=.03, p=.01,95 \%$ CI $[-.14,-.01]$. Therefore, attachment avoidance shows a tendency to decrease only the husband's own marital satisfaction via his own marital power.

\section{Discussion}

The main purpose of this study was to investigate the relationship between attachment insecurity (attachment anxiety or avoidance) and marital satisfaction and the mediating role of marital power within this relationship. It was found that for wives, attachment avoidance directly predicts marital satisfaction; whereas for husbands, attachment avoidance predicts marital satisfaction not only directly but also through low marital power. The direct effect of attachment avoidance on marital satisfaction is consistent with previous studies (e.g., Harma \& Sümer, 2016; Li \& Chan, 2012). However, it was found that for both husbands and wives, attachment anxiety did not directly predict marital satisfaction. Harma and Sümer (2016) asserted that for collectivist cultures, attachment avoidance was a greater risk factor than attachment anxiety because intimacy and harmony seemed to be very important in this kind of societies. On the contrary, anxious attachment with behavioral characteristics such as clinging to the spouse may not be seen as abnormal as they would in western societies (Harma \& Sümer, 2016). Therefore, anxious attachment may not be a risk factor marital satisfaction in this kind of societies. Harma and Sümer (2016) have found that in Turkey, which also bears collectivist properties, avoidant attachment strongly predicts marital satisfaction, whereas anxious attachment does not. Our findings are consistent with those of Harma and Sümer's (2016).

Results indicated that for both wives and husbands, anxious attachment predicts marital satisfaction via marital power. Accordingly, individuals with a high anxious attachment level perceive themselves less powerful in their marriages and this, in turn predicts low marital satisfaction. Mikulincer and Shaver (2007) claimed that individuals with high attachment anxiety were too busy with their relationships and they had very high rejection 
sensitivity. It may be possible to say that individuals with a high attachment anxiety might also be more selective to perceive the situations where they cannot influence their spouses. This, in turn, may lead individuals to perceive to be less powerful in their marriages and obtain less satisfaction from it. The present study reveals one of the processes by which attachment anxiety influences marital satisfaction.

In addition, in the present study, attachment avoidance was expected to predict marital satisfaction via marital power as well. However, this expectation was confirmed only for the husbands. Accordingly, for husbands as the attachment avoidance increases, marital power decreases, which in turn results in low marital satisfaction. For the wives, no significant mediating effect was found in this association. One reason for the difference between men and women was that although the effect of attachment avoidance on marital power was found significant for husbands, it was not the case for the wives. In other words, as attachment avoidance increased, marital power tended to decrease for husbands, whereas this association was not significant for wives. This difference between genders might result from the masculine norms. Namely, it was stated that being more powerful had a central value in masculinity, whereas having less power was a threat to the masculinity (Overall, Hammond, McNulty, \& Finkel, 2016). Avoidant husbands may also desire to have more power but at the same time they may lack intimacy to attain this. That is, avoidant husbands may perceive themselves to have less power because they do not have enough intimiacy with their viwes (Mikulincer \& Shaver,2007) to influence them. This may in turn make them get less satisfaction from their marriages. As they are not expected to have more power, it can be stated that wives with high avoidant attachment level may not face conflicts like the husbands. The gender difference revealed in our study supports the idea that gender roles may affect the relationship between avoidant attachment and marital power. Yet, we suggest that this relationship should be examined in more detail in future studies.

This study has certain limitations as well. First of all, our study is a correlational one, which prevents inferring a causality among the variables. With the help of future longitudinal research, more reliable results on the subject will be available. In addition, our study did not include questions about the individuals' relationship history such as the number of previous relationships or whether they had a previous marriage. Future research, which will measure and test such factors, will be more representative. Moreover, in our study, marital power was used as unidimensional as in previous studies (e.g., Oka et al., 2016). However, for future research correla- tion of attachment dimensions with power outcomes and power processes can be evaluated in more detail by using marital power as two-dimensional. 